\title{
Technical Efficiency Evolution Model of the Integration of Information Technology and Manufacturing Technology
}

\author{
Dingjuan $\mathrm{Wu}^{1}$ and Jianhua $\mathrm{Zhu} \mathbb{D}^{2}$ \\ ${ }^{1}$ School of Health Management, Guangzhou Medical University, Guangzhou 511436, China \\ ${ }^{2}$ School of Business Administration, South China University of Technology, Guangzhou 510641, China
}

Correspondence should be addressed to Jianhua Zhu; 201710105331@mail.scut.edu.cn

Received 24 September 2019; Revised 19 February 2020; Accepted 4 March 2020; Published 13 April 2020

Academic Editor: Dimitris Mourtzis

Copyright $(2020$ Dingjuan Wu and Jianhua Zhu. This is an open access article distributed under the Creative Commons Attribution License, which permits unrestricted use, distribution, and reproduction in any medium, provided the original work is properly cited.

The integration of information technology and manufacturing technology (IOITMT) is a strategic idea proposed by China. As the smallest unit of integration, manufacturing enterprises can be seen as the root of IOITMT. However, the current situation of IOITMT in China shows that intelligent manufacturing still has a long way to go and that the implementation effect of IOITMT requires urgent improvement. The dynamic evolution of IOITMT is accompanied by the integration and coevolution of internal technologies and also affects the performance of enterprises. Taking technical efficiency as a measure of IOITMT, the purpose of the current study is to develop an internal dynamic evolutionary mechanism framework for IOITMT of a single cycle in manufacturing enterprises. The framework is based on the theory of self-organization and convergence and uses convergence theory to discuss the evolution mode of technical efficiency in the three stages of IOITMT under the guidance of order parameters. This paper finds that the technical efficiency of IOITMT is influenced by the ratio of convergence parameters $\left(r_{1} / r_{2}\right)$, and adjusting the convergence intensity can effectively improve the performance of enterprises. Hence, this paper provides important theoretical guidance for the advancement of IOITMT of Chinese manufacturing enterprises.

\section{Introduction}

Germany's "Industry 4.0" strategy clearly aligns with China's "IOITI" strategy. Compared with Germany's industrial development strategy, the analysis of the release motivation of these two strategies, their development philosophies, and their strategic directions is all very similar. Under the premise that manufacturing technology lags behind information technology, the two strategies both attempt to improve the international competitiveness of domestic manufacturing enterprises through the deep integration of informatization and industrialization. The high compatibility between "Made in China 2025" and Germany's "Industry 4.0" has provided references for China's manufacturing transformation and upgrading. However, comparatively, Germany has a more perfect market mechanism, a more mature manufacturing enterprise sector, stronger market regulation, enterprise innovation, and R\&D capability. Chinese enterprises have more active autonomy and spontaneity in the implementation of "Industry 4.0," highlighting a driving force that cannot be ignored. However, the real economy of China's manufacturing industry is relatively weak, and there are significant differences in the production modes between and within industries, from manual workshops to mechanized factories, to highly automated large-scale manufacturing enterprises. As such, IOITMT markedly differs from that of the "Industry 4.0 " strategy in terms of implementation. The main driving force comes from the government's leadership and financial support subsidies. Most enterprises, especially at the level of small and medium-sized, act as policy learners and implementers. Therefore, the internal role of the enterprise merits significant attention.

As an important measure of national economic transformation and upgradation, arguably, the IOITMT should not only remain at macrolevel but also be implemented by microenterprises. As the main terminal executor, IOITMT of manufacturing enterprises should be fully valued. At 
present, the overall effect of IOITMT is not optimistic, with its specific integration status and problems reflected in several aspects, as follows.

First, there is an objective problem of the shortage of funding and skilled professionals, especially in small- and medium-sized enterprises, which has always been one of the major factors restricting the implementation of integration. Given the vigorous promotion of the IOITMT, enterprises actively propose development strategies and seek government support and financial subsidies, which may help to alleviate some of their financial pressure. In addition, prioritizing skills introduction and enterprise staff training is also helpful in solving the problem of human resources demand caused by the integration and sustainable development of the two industries.

Secondly, there is a subjective problem: those at a senior level in enterprises tend to have insufficient understanding of, and an unclear construction strategy for, the IOITMT. (1) Although many manufacturing enterprises have entered the virtuous cycle of IOITMT, many managers, especially of small- and medium-sized enterprises, still have insufficient understanding of the necessity and urgency of IOITMT. Hence, the managers' traditional manufacturing concepts have not been reversed in time. (2) According to studies of manufacturing enterprises, with which our team has had long-term engagement, some enterprises' understanding of IOITMT is still limited to primary information configuration, and information technology has not been extensively applied to enterprise management. It is difficult to realize improvements in enterprise performance via information technology in the later stages due to the hidden, technical challenges in the initial stages of such integration. (3) In IOITMT planning, there has been a failure to perceive the differences between enterprises and correctly implement the application of information technology according to each enterprise's unique characteristics. The "IT productivity paradox" caused by such improper investment can seriously damage enterprise managers' confidence in the application of information technology and their enthusiasm for investment. Furthermore, the "IT productivity paradox" influences subsequent investment in IOITMT.

In line with both the real-life background and the relevant theory, research on the dynamic evolution of the IOITMT of manufacturing enterprises conforms both to enterprises' practical needs and research needs, as shown in Figure 1. As such, the dynamic evolution of IOITMT is the focus of the current study. Firstly, in general, the integration level cannot be fixed at a specific value with the deepening or mutation of fusion. While scholars have widely adopted the evaluation model and the integration level method, the process of integration determines the dynamic of the integration level. As such, an in-depth discussion of the level of evolution can more comprehensively grasp the law of fusion. Secondly, the process and continuity of the integration of manufacturing technology and information technology pose new challenges to the study of evolution law. The nature, fusion mode, and content of technology fusion need to be reexamined, and new attempts also need to be made in terms of how best to explore the maintenance of the constantly changing fusion state. Finally, the evaluation models in existing studies have already discussed the set of influencing factors of the IOITMT. The overall dynamic evolution of the fusion system needs to contain these changes in the influencing factors, with the discussion of the internal relationship between influencing factors being the basic problem of dynamic research.

Based on these considerations, research on the dynamic evolution law of IOITMT can be divided into the following three subproblems:

(1) What is the law of the dynamic evolution of the integration level of manufacturing enterprises? How should an enterprise implement this law?

(2) What is the essence of the dynamic evolution of the integration of internal manufacturing technology and information technology? How can the dynamics of constantly updated fusion states be considered?

(3) How do the influencing factors of IOITMT influence integration? Are there key elements? How should an enterprise grasp these key elements so as to promote the IOITI?

It is hoped that this research can be of significance to the development of IOITMT and help manufacturing enterprises with the following challenges: how to recognize the essence and significance of IOITMT under the new situation of economic development? how to understand the importance of spontaneous internal breakthroughs? how to promote the smooth implementation of IOITMT macropolicies from the perspective of microenterprises? how to grasp the key factors according to their own development and predict the development trend of the enterprise's IOITMT scientifically, step into the path of healthy and benign development, and realize the sustainable development of enterprises?

The rest of this paper is organized as follows. Section 2 summarizes the definitions of enterprise technology integration and the related research pertaining to enterprise technology integration models. Section 3 summarizes the research methodology employed. Section 4 analyzes the dynamic integration mechanism between manufacturing technology and information technology. Section 5 provides the definition of the technical efficiency of IOITMT. Section 6 establishes the self-organizing evolution model of technological efficiency in IOITMT. On the basis of this model, Section 7 establishes the technical convergence model under the order parameter slaving. On this basis, the convergence model under uncertain convergence parameters is discussed, and the impact of different convergence parameters on technical convergence is verified by simulation analysis. Finally, the paper concludes with a discussion of this study's contribution to research and practice and identifies several future research directions.

\section{Literature Review}

2.1. The Definition of Enterprise Information Technology Integration. Even though international academic circles 


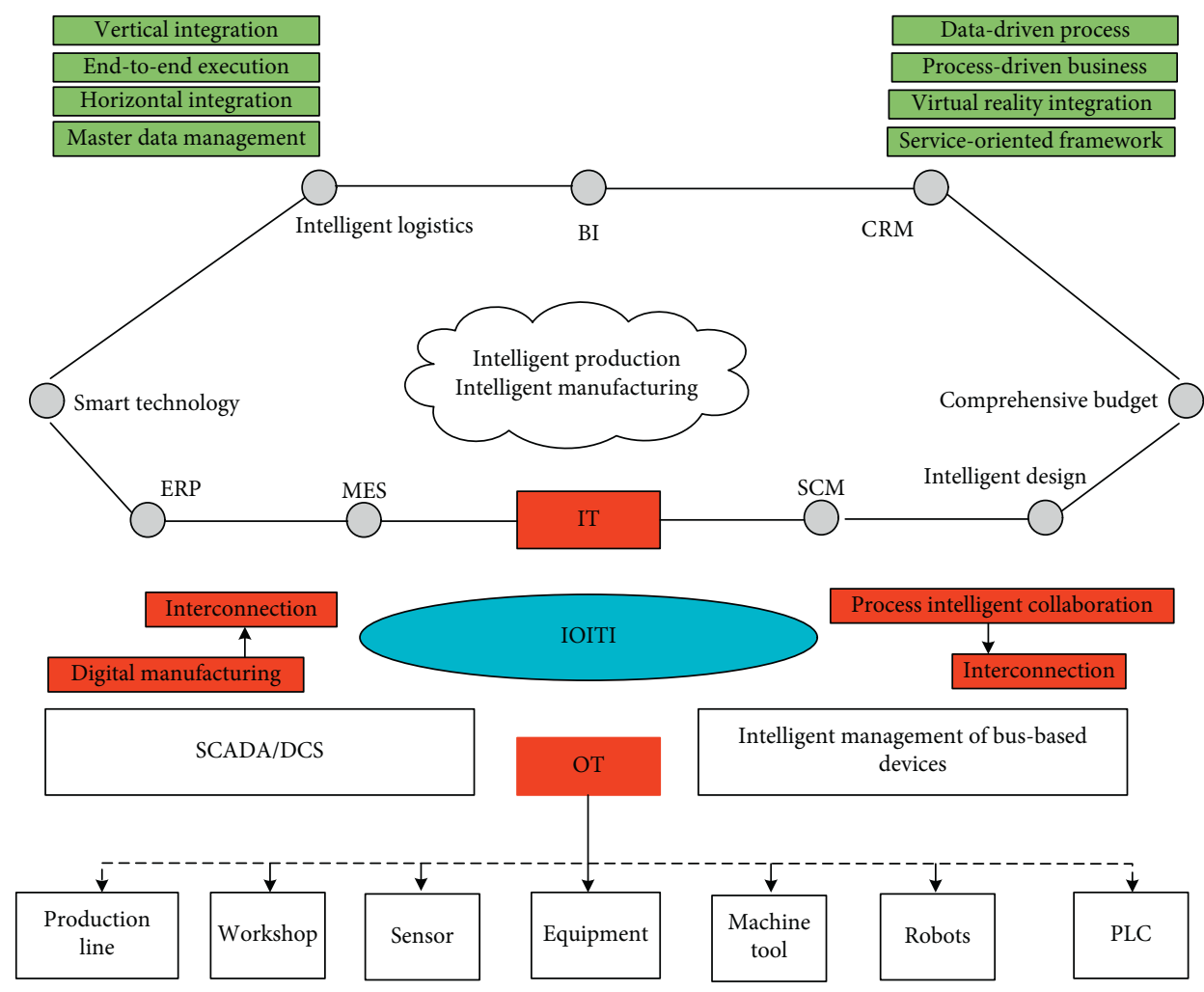

FIGURE 1: Integration of intelligent manufacturing information systems.

began discussing the concept of enterprise information technology integration in the late 1970s, no consensus on the definition has been reached. Among these debates, common references include "alignment" [1], "fit" [2], and "integration" [3]. Generally, the commonly accepted usage is "alignment." Scholars began to turn their attention from static "alignment" to "integration" based on process research. The content of enterprise information technology integration has since been interpreted in various forms by numerous scholars, according to differences in research perspectives. Through the literature review undertaken as part of the current study, representative definitions were selected, as shown in Table 1.

Although scholars have different understandings of "information technology convergence" based on different emphases on corporate vision, strategy, structure, and plan, a broad consensus can be seen in terms of "information technology supporting enterprises towards the same goal."

\subsection{Research on the Enterprise Information Technology In-} tegration Model. Early research on enterprise information technology matching originates from strategic enterprise planning and long-term planning and its theory mainly comes from the Business Systems Planning (BSP) of information technology, which was proposed based on IBM's practical experience of information system development. At that time, the main view was that integration referred to the top-down and bottom-up interaction process between information technology and enterprises, and that the information technology plan should conform to the strategic needs of an enterprise's business concerns. Using the case study method, Pyburn [9] pointed out that factors such as the decision-making mode of senior executives, enterprise business dynamics, complexity of information systems and management tasks, and the state and location of information technology managers were key to the success or failure of a strategy of information technology integration. Factors combined with fusion and fusion and integration path analyses are researched, and Broadbent and Weill [10] proposed a fusion model based on information technology and enterprise process through empirical research. Furthermore, Henderson and Venkatraman [4] constructed a more complete strategic alignment model (SAM) of information technology and established a theoretical framework for information technology and strategic enterprise planning, reflecting mutual support within the interaction process of an enterprise's business concerns and its information technology.

SAM $[11,12]$ is divided into four parts, as shown in Figure 2.

The SAM framework is divided into four areas: enterprise strategy, referring to the positioning and selection of enterprises; information technology strategy, referring to the positioning and selection of enterprises in the information technology market; enterprise organizational structure and process, referring to internal resources in terms of internal structure, business process, and management skills; and information technology architecture and process, referring to information system architecture, information system 
TABLE 1: Definition of enterprise information technology integration.

\begin{tabular}{|c|c|}
\hline Literature resources & Definition of information technology integration \\
\hline $\begin{array}{l}\text { Henderson and } \\
\text { Venkatraman [4] }\end{array}$ & $\begin{array}{c}\text { The consistency of enterprise strategy and information technology strategy, enterprise organizational } \\
\text { structure, and information technology organizational structure }\end{array}$ \\
\hline Reich and Benbasat [5] & $\begin{array}{c}\text { Information technology supporting and sharing the status of the tasks, goals, and plans of the enterprise } \\
\text { strategy }\end{array}$ \\
\hline Luftman and Brier [6] & $\begin{array}{c}\text { Applying information technology to an organization in an appropriate and timely manner that is consistent } \\
\text { with the organization's strategy, goals, and needs }\end{array}$ \\
\hline Campbell [7] & Information technology and enterprises work towards common goals \\
\hline Shi and Pan [8] & $\begin{array}{l}\text { The business of the enterprise and its information technology are comprehensively combined to achieve a } \\
\text { connection at the strategic, organizational structure, and operation levels, so as to provide support for the } \\
\text { enterprise's profitability }\end{array}$ \\
\hline El-Mekawy et al. [1] & Information technology is optimized to maximize business value \\
\hline
\end{tabular}

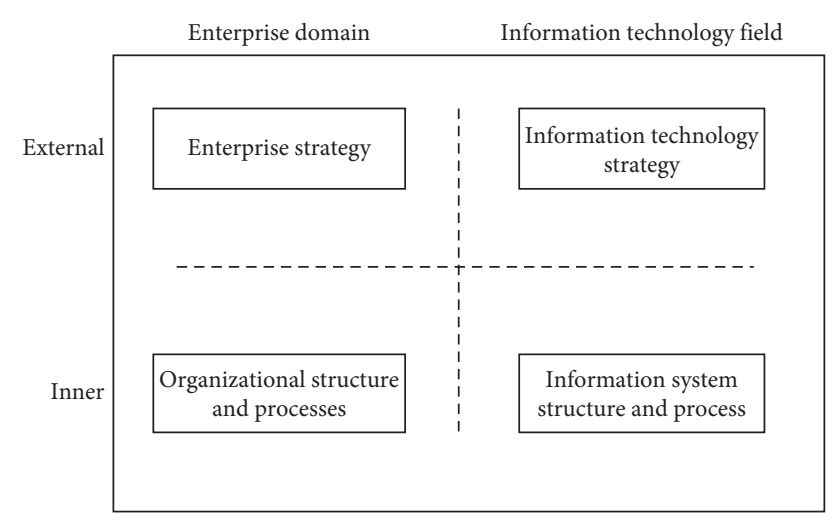

FIgURE 2: SAM framework.

development and maintenance, information technology, and human resources, among other aspects. The specific contents and perspectives of the four integration modes in the business domain and information technology domain at the two levels are shown in Table 2.

SAM focuses on the integration and communication between the internal and external environment, thus laying a research foundation for information technology, information system, and enterprise strategy and spawning many empirical studies. In later research, many related studies were based on SAM, such as those relating to the fusion model [11, 13], degree of integration [14], impact factors [15], and impact effects [16].

On the basis of SAM, the most representative achievement may be the eight-dimensional model of the strategic integration of an information system proposed by Chan et al. [17]. The eight dimensions are aggressive support, analysis support, internal defense support, external defense support, future support, forward support, risk avoidance support, and innovation support. This model reflects the strategic significance of information technology in a comprehensive and detailed way. Subsequently, Copeland et al. [18] modified the eight-dimensional model into a four-dimensional model: activity support (comprising the aggressive support, internal defense support, forward support, and innovation support dimensions), analytical support (comprising the analysis support and risk avoidance support dimensions), defense support (comprising the external defense support dimension), and forward support. Several of the dimensions constructed by Chan et al. have also generated research results from different perspectives, such as information technology innovation in the innovation dimension [19] and empirical research on the improvement of enterprise operation efficiency through the use of information technology [20]. Mclaren et al. [21] proposed a multidimensional strategic integration model of enterprise strategy and information system capability, which, arguably, enables a more comprehensive and specific measurement of information technology integration. Seman and Salim [22] considered the research vulnerability of the influencing relationship and influencing mode of the factors of information technology integration on organizational performance, proposing a theoretical model for the influence of these factors on performance based on the four-dimensional model, and provided an important research tool for relevant empirical research.

Recent research results have begun to reflect on the practical problems of SAM application. These challenges are mainly reflected in the following three aspects: (1) SAM's premise requires the existence of a formal business and information technology strategy. Salaheddine and Ilias [16] argued that "strategic integration" requires a set of highquality information technology. Therefore, they proposed to integrate the PDCA cycle during SAM implementation. Goepp and Avila [23] proposed the extended strategic alliance model and development process, and they support the systematic study of the interplay between business, information technology, and product design or manufacturing. (2) While the relevant models derived from SAM are based on the premise that practitioners understand the models most suited to enterprises, the reality is often counterproductive. In response to this problem, El-Mekawy et al. [1] proposed a research framework for model selection to help practitioners determine their optimum model and evaluated seven large Swedish enterprises with this analytical framework. The study confirmed the practical feasibility of the selection method and the theoretical framework. Dutot et al. [24] obtained interview data through an in-depth investigation of three company cases and then used behavioral network theory as the theoretical framework to help them understand and interpret the interview data. On this basis, a new, conceptual, nonfunctional model was presented that 
TABLE 2: Four SAM patterns.

\begin{tabular}{|c|c|c|c|c|}
\hline Pattern & Path & Main ideas & $\begin{array}{c}\text { Requirements for senior } \\
\text { management }\end{array}$ & $\begin{array}{l}\text { Enterprise status of information } \\
\text { technology }\end{array}$ \\
\hline $\begin{array}{l}\text { Strategic } \\
\text { execution } \\
\text { model }\end{array}$ & (1)-(3)-(4) & $\begin{array}{l}\text { The enterprise operation } \\
\text { strategy is the driving force of } \\
\text { the enterprise }\end{array}$ & $\begin{array}{l}\text { Senior management sets the } \\
\text { corporate strategy and determines } \\
\text { the organizational structure and } \\
\text { processes of the enterprise }\end{array}$ & $\begin{array}{c}\text { Information technology } \\
\text { departments are subordinate to } \\
\text { enterprise strategy }\end{array}$ \\
\hline $\begin{array}{l}\text { Technical } \\
\text { potential model }\end{array}$ & (1)-(2)-(4) & $\begin{array}{l}\text { Information technology } \\
\text { supports enterprise strategy } \\
\text { execution }\end{array}$ & $\begin{array}{l}\text { Senior management needs IT } \\
\text { education, fully understands the role } \\
\text { of information technology, and is } \\
\text { able to formulate information } \\
\text { technology strategy }\end{array}$ & $\begin{array}{l}\text { Information technology personnel } \\
\text { are responsible for building and } \\
\text { designing an information } \\
\text { technology organizational } \\
\text { framework that matches the external } \\
\text { environment }\end{array}$ \\
\hline $\begin{array}{l}\text { Competitive } \\
\text { potential model }\end{array}$ & (2)-(1)-(3) & $\begin{array}{c}\text { Emphasizes the transformation } \\
\text { and promotion of an enterprise } \\
\text { strategy through information } \\
\text { technology }\end{array}$ & $\begin{array}{l}\text { Business executives are competent in } \\
\text { reviewing the information } \\
\text { technology market based on business } \\
\text { objectives and helping companies } \\
\text { improve their existing governance } \\
\text { models and operational strategies }\end{array}$ & $\begin{array}{c}\text { Managers assist senior management } \\
\text { with IT, acting as technical analysts } \\
\text { and consultants }\end{array}$ \\
\hline $\begin{array}{l}\text { Service level } \\
\text { model }\end{array}$ & (2)-(4)-(3) & $\begin{array}{l}\text { Leading information } \\
\text { technology is the enterprise's } \\
\text { strategic goal in order to } \\
\text { improve their service level }\end{array}$ & $\begin{array}{l}\text { Senior management can optimize } \\
\text { the business and information } \\
\text { technology resource allocation to } \\
\text { ensure the enterprise's rapid } \\
\text { response to the information } \\
\text { technology market }\end{array}$ & $\begin{array}{l}\text { Information technology } \\
\text { management personnel enter the } \\
\text { senior management level of the } \\
\text { enterprise and monitor the } \\
\text { enterprise's operation, in accordance } \\
\text { with the instructions }\end{array}$ \\
\hline
\end{tabular}

integrated several translated strategic alignment models (TSAMs). This model may help to promote consistency at a key level. (3) SAM has been the classic and most widely used model of information technology integration over the past 20 years. However, there has consistently been a significant gap between the practical achievements and theoretical expectations surrounding SAM's relevant research results. With regard to this discrepancy, Renaud et al. [25] found that the model's application and practice were artificially limited because researchers had not challenged the basic assumptions and premises of SAM. As a result, these practical problems have engendered new requirements in order for the models and research methods to keep pace with the times.

Thus, in reviewing the existing literature, it is evident that, while research on IOITMT has accumulated many results, there is still the need for an ongoing, in-depth discussion, for the following reasons:

(1) Research results need to be localized. While the research background of IOITMT in developed countries is information technology integration in enterprises, there is still a certain gap between Chinese manufacturing enterprises and manufacturing enterprises in developed countries, meaning that the latter research results cannot be directly applied to IOITMT of Chinese enterprises. However, existing research on enterprise information technology also opens up the opportunity for the current study.

(2) Related research is insufficient. In the current global economic context, the transformation and upgradation of the manufacturing industry have become a top priority, with an imperative for the spillover and development of the relevant research results pertaining to manufacturing enterprises. However, most international studies of information technology integration are based on the application of enterprise information technology after the completion of industrialization and do not pay much attention to the particularity of manufacturing enterprises. In addition, most considerations relating to IOITMT, both in China and internationally, are based on information technology matching in terms of strategy, plan, process, and project, essentially focusing on the integration of information technology and management from the perspective of enterprise informatization. However, at the core of IOITMT of manufacturing enterprises is the dynamic integration of manufacturing technology and information technology. Therefore, further research is needed on the IOITI based on the characteristics of manufacturing enterprises.

(3) Research on the dynamic evolution of IOITMT is still in need of in-depth discussion. On the one hand, IOITMT is a dynamic process and, thus, the application of static research results will certainly solidify the thinking of enterprises. It is also hard to explain the changing behavior of enterprises. Therefore, it is necessary to establish a research perspective on intrinsic dynamic characteristics. On the other hand, the dynamic integration of informatization and industrialization has another implication; integration is constantly broken and rebuilt under dynamic technological changes. Most existing studies are based on dynamic research conducted with reference to established information technology, without considering the technological progress of 
information technology and the dynamic integration process it brings. Moreover, the research focus of dynamic evolution is geared towards grasping the essential laws. Most existing studies are based on a discussion of the conceptual and simulation models. Although some scholars have offered the viewpoint of coevolution, these perspectives have been limited to the description and analysis of the evolution mechanism. Therefore, the establishment of a more suitable model will not only further improve the theory of applicability and scientific theory but also the enterprise integration of the dynamic evolution of the research system. In addition, while the influencing factors of the integration of enterprise globalization have been repeatedly discussed by both Chinese and international scholars, the influencing ways and means of IOITMT of enterprise globalization have been rarely addressed. In addition, many factors are bound to play different roles in the different development stages of an enterprise. Therefore, it is of great application value to grasp these key factors at different stages and understand their evolution trend for the integration of informatization and industrialization.

\section{Research Methods}

The essence of IOITMT is the dynamic integration of manufacturing technology and information technology. In order to reveal the rules and essence of the dynamic evolution of IOITMT, the current paper takes technical efficiency as the index to measure the degree of integration necessary to establish a self-organizing evolution model. After the order parameters are determined and analyzed, the three-stage evolution model of technical efficiency under the guidance of order parameters is discussed, with reference to convergence theory.

The internal development of self-organization is the way in which a system evolves and forms the theoretical basis of the internal driving force of manufacturing enterprises. "Self-organization" is different from "heteroorganization." The key point is whether or not the organization is spontaneous. "Heteroorganization" evokes the study of microobjects, focusing on the analysis of macrocontrol strategies beyond microobjects. However, self-organization means mapping the external environment onto internal parameters, deeply analyzing the systemic mechanism from the internal perspective of the research object, and proposing more targeted strategic suggestions for the research object.

To some extent, self-organization renders the system closed. Since the evolution of self-organizing systems is, effectively, the process of the collaborative competition of the system's internal factors, in some sense, a virtual boundary is drawn for the discussion of the system.

Order parameters play a key role in the evolution of selforganizing systems. Order parameters, as the invisible hands that govern systems evolution, are only valid for self-organizing systems. The evolution law of the system can be described by determining the order parameter and the order parameter equation, and the short-term prediction can be made accordingly. Order parameters are of great guiding significance to the construction strategy selection of IOITMT in manufacturing enterprises.

The concept of convergence originates from the mathematical discipline of natural science, and its original meaning is that of convergence. The purpose of the initial research on convergence theory is to verify a hypothesis proposed by neoclassical economic growth, namely, the hypothesis of the relationship between the economic growth rate and initial level. Economic growth theory holds that "convergence" indicates that the income gap between countries or regions is decreasing and that the economic growth rate of an economy is positively correlated with the distance between the economic state and the stable state, which is also the basic assumption of the neoclassical economic growth model. Enterprises' manufacturing and information technologies do not exist independently of one another but remain dependent. The integration of industrialization and informatization is the superposition evolution process of the interaction between industrialization and informatization.

The existing research methods are mainly from the following two aspects: (1) the statistical research; (2) the dynamics model and simulation analysis according to certain indexes. Data statistical method is result oriented and cannot reveal the inherent law of evolution. The existing dynamic modeling methods are based on dynamic research conducted with reference to established information technology, without considering the technological progress of information technology and the dynamic integration process it brings. Unlike existing dynamics modeling methods, we use the method of synergetics to determine order parameter equation of dynamic model established in this paper because the order parameter equation can reveal the internal evolution of research object. In addition, in order to solve the problem that does not consider the technological progress of information technology and the dynamic integration process it brings, firstly this paper describes the integration of information technology and manufacturing technology with the definition of matching, then introduces convergence theory to describes the dynamic relationship between information technology and manufacturing technology with heterogeneous convergence model, and finally analyzes the three-stage evolution model of technical efficiency under the guidance of order parameters by convergence model.

\section{Analysis of the Dynamic Integration Mechanism of IOITMT}

4.1. The Interaction between Manufacturing Technology and Information Technology. Two aspects of the integration in manufacturing enterprises are technology matching and the dynamic and collaborative development of technology. In this sense, IOITMT of manufacturing enterprises can be regarded as the dynamic matching of information technology and manufacturing technology.

As shown in Figure 3, on the one hand, the application of information technology promotes the intellectualization of 


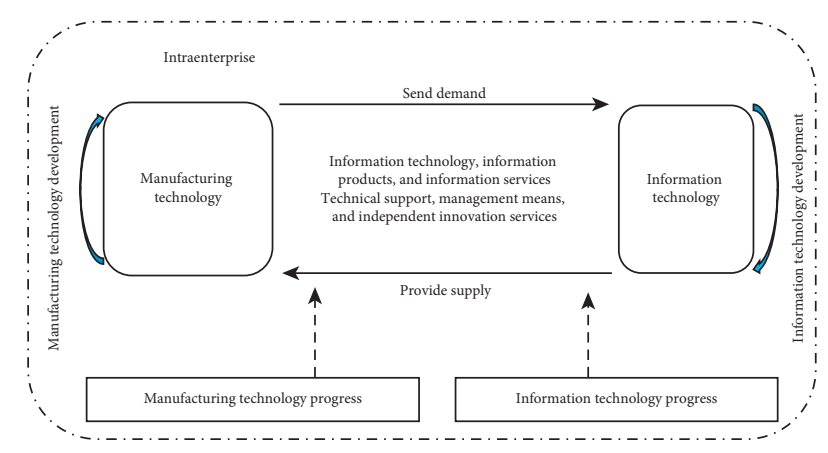

FIGURE 3: Dynamic integration model of IOITMT.

manufacturing technology and management, improves management efficiency and customer satisfaction, reduces operating costs, and optimizes production structure. The technical demand generated by the development of manufacturing technology encourages information technology to follow, progress, or surpass and advances the information technology according to the needs of the particular manufacturing enterprise. On the other hand, the development and progress of enterprises' internal technologies are inevitably influenced by environmental technology, except that it is the mutual promotion between internal manufacturing technology and information technology. The introduction of new technology from the outside inevitably drives the progress of internal technology. Under the cyclic effect of both an internal and external technical environment, both the manufacturing and information technologies of enterprises are constantly improved and updated, and the technical level continuously improves.

It is worth noting that manufacturing technology and information technology tend to be abstracted for the purposes of discussion based on research needs. However, in practice, manufacturing technology and information technology are inseparable. Many manufacturing technologies are integrated into information technology, which is the root of integration and the main reason driving the current discussion of technology integration. In other words, the manufacturing technology integrated with information technology is still manufacturing technology, and the information technology currently being discussed includes information technology that has not yet been integrated with manufacturing technology. Examples of the latter include a scenario where an enterprise has not yet integrated its manufacturing technology with software or CNC technology, or, alternatively, where the integration of information technology, such as communication technology or information systems, and manufacturing technology mainly focuses on their matching and cooperation.

4.2. Content and Mode of IOITMT. Information technology comprises many aspects. According to its broad definition, this type of technology can be considered to be a variety of tools and rule systems based on the purpose of developing and utilizing information resources. In line with its particular manifestation, information technology can be divided into hard technology and soft technology. Hard technology, or hardware, refers to all kinds of information equipment and their functions, including communication equipment, computers, and communication satellites. Soft technology, or software, refers to various methods and skills for information acquisition and processing embedded in hardware, such as data analysis technology, computer software technology, sensing technology, and control technology, as well as new intelligent technologies such as the Internet and cloud computing.

As shown in Figure 4, IOITMT is reflected in an enterprise the entire operation process, mainly in the different types of information systems of enterprise operation support, embedded information technology support for mechanical production, numerical control technology support for the manufacturing process and manufacturing automation, Internet technology support for electronic commerce, network technology and computer-aided design technology support for the innovation of enterprise technology, Internet technology support for enterprise equipment production, and product management, making the cloud a source of support for enterprise operation.

\section{Technical Efficiency Definitions of IOITMT}

5.1. The Process of the Concept Derivation of Technical Efficiency. For the purposes of this study, IOITMT was divided into three stages, as shown in Figure 5: industrialization promotes informatization based on industrialization, industrialization and informatization reinforce each other, and informatization drives industrialization. Manufacturing enterprises are organizations that have manufacturing at their core. Therefore, these three stages can be implemented in microenterprises and understood as manufacturing technology that promotes the information technology stage, the manufacturing technology and information technology stage of "stalemate," and the stage of information technology driving manufacturing technology. Of course, management, culture, system, and other factors also have a considerable effect on the integration of manufacturing enterprises and IT. In order to highlight the characteristics of manufacturing enterprises, other technologies can be regarded as manufacturing-related technologies, and their influence can also be reflected in the technical efficiency of manufacturing technology and the degree of IOITMT.

It is difficult to realize the measurement of manufacturing technology and information technology because their boundary is difficult to set; that is to say, IOITMT is, essentially, a question of technical efficiency. Based on this idea, the current paper discusses the model and order parameters of the integration technology efficiency of manufacturing enterprises.

5.2. Definition of the Technical Efficiency of IOITI. Technical efficiency was first proposed by Farrell [26] and Afriat [27], and the concept is closely connected with the concept of the production frontier. The production frontier refers to the boundary surface formed by the 


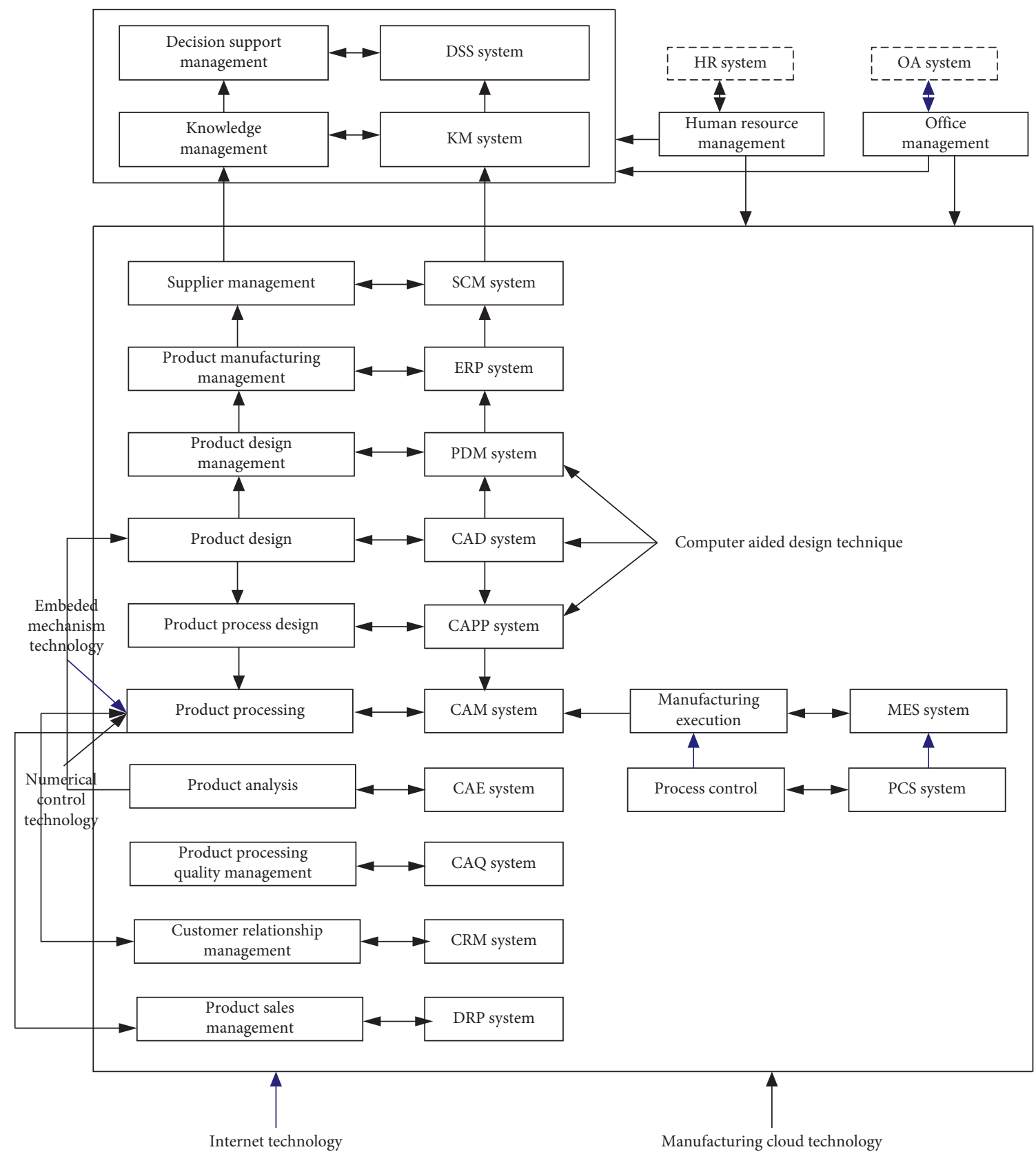

Figure 4: Main content and mode of IOITMT.

maximum output set corresponding to the proportion of all technical inputs at a given technical level. Also called the technology that belongs to the production frontier is effective technology; otherwise, the technology is invalid technology. Technical efficiency is defined as the ratio between the actual output and the maximum output of the decision-making unit (DMU) under the same factor input, and its value is the ratio between the actual output under the same factor and the optimal output with effective technology on the frontier. Technical efficiency quantitatively describes the gap between the actual output and the optimal output under the condition of equal factor input; the closer to the production frontier, the higher the technical efficiency [28].
The technical efficiency of manufacturing and information technologies is not explicit, but internal to the enterprise. As such, the corresponding output cannot clearly be defined. It is necessary, therefore, to find a reasonable angle with which to determine the connotation of the technical efficiency of both types of technology. In combination with the aforementioned understanding of technical efficiency, the technical efficiency of manufacturing enterprises refers to the effectiveness of their input and output. In other words, the technical efficiency of manufacturing enterprises is the effectiveness of output under total factor production. The explicit technical efficiency of manufacturing enterprises can be considered as the comprehensive embodiment of manufacturing technical efficiency and information 


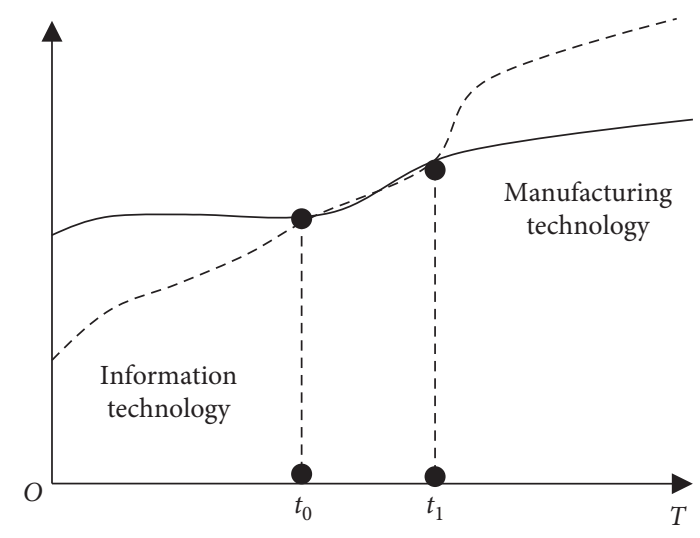

FIgURE 5: Technological evolution path of IOITMT.

technology efficiency. According to the barrel principle, the two different kinds of technical efficiency should show the least technical efficiency. Therefore, the stage in which manufacturing technology drives information technology is often when information technology is the most unfamiliar to enterprises, for which reason the enterprise's technical efficiency can be considered as the embodiment of information technology efficiency. Conversely, at the stage in which information technology promotes manufacturing technology, the enterprise's technical efficiency is considered to be equal to the technical manufacturing efficiency. Thus, the following definition can be given.

Definition 1. The technical efficiency of a manufacturing enterprise is equal to the lowest of internal manufacturing technical efficiency value and information technology efficiency value.

The production factors of an enterprise include human resources, capital, land, manufacturing technology, information technology, and other inputs, and the output is multidimensional. In order to render the model devised in the current study more intuitive, a one-dimensional output is applied. This is merely a reduction of the dimension and do not affect the conclusion. As shown below, $E$ is used to represent the production factor set, $Q(E)$ is the output corresponding to the production factor set $E$, and $Q^{*}(E)$ is the maximum output corresponding to the frontier of the factor set $E$. Thus, the technical efficiency of the manufacturing enterprise is $Q / Q^{*}$.

As shown in Figure 6, when the return to scale of a manufacturing enterprise is assumed to be constant and input factors are simplified to a type, the arrow starting from the origin represents a production frontier with constant returns to scale and is composed of the maximum output of all factors, making it easy to calculate the technical efficiency of the enterprise.

The information technology efficiency and manufacturing technology efficiency of manufacturing enterprises are denoted by $N_{1}$ and $N_{2}$, respectively. Therefore, in the stage of manufacturing technology driving information technology, information technology efficiency is identified as the technical efficiency of manufacturing enterprises. The following steps

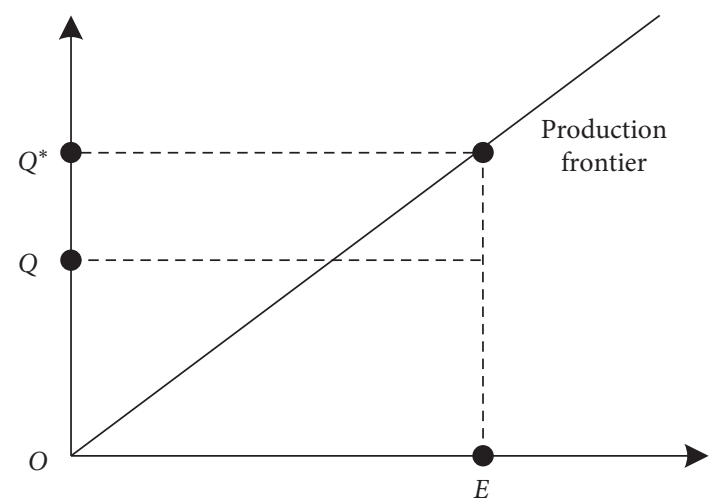

Figure 6: Technical efficiency measurement route of manufacturing enterprises.

are undertaken to obtain the definition of this stage: information technology efficiency refers to the enterprise technical efficiency under the total factor production of manufacturing enterprises, $N_{1}=\mathrm{Q} / \mathrm{Q}^{*}, N_{1} \leq 1$. The initial production factor set is denoted as $E_{0}$, the actual output is $Q_{0}\left(E_{0}\right)$, and the maximum output on the production frontier corresponding to factor set $E_{0}$ is $Q_{0}^{*}\left(E_{0}\right)$. Thus, the initial information technology efficiency can be expressed as $N_{1}^{0}=\left(Q_{0} / Q_{0}^{*}\right)$.

The manufacturing technology and information technology of manufacturing enterprises are integrated, and both are counted as production factors in the technical efficiency measurement of an enterprise, with an overlap in the extraction and measurement of production factors. Even without the integration of manufacturing technology, the elements are distributed across all departments and all internal links of the enterprise are difficult to refine. Therefore, the initial manufacturing technical efficiency, $N_{2}^{0}$, includes the following considerations: (1) in order to maintain the same scale of information technology efficiency, the concept of manufacturing technology efficiency should be introduced based on the relationship between information technology and manufacturing technology. (2) In this stage, the efficiency of manufacturing technology is higher than that of information technology. The selection of the particular information technology depends on the existing manufacturing technology and takes the current manufacturing technology as the benchmark for all aspects of adjustment and construction. It can be considered that the existence of the current manufacturing technology is in line with enterprises' needs and business requirements and has a reasonable optimized technical structure. (3) Driven by manufacturing technology, information technology gradually penetrates into manufacturing technology with manufacturing technology as the guiding element and gradually integrates manufacturing technology so as to give full play to the matching of manufacturing technology and information technology to achieve effective technology. Driven by manufacturing technology, the goal of integrating realizes technical efficiency as 1 . Therefore, for the sake of further discussion, the following definition is provided.

Definition 2. When multiple technologies are integrated, and if they are fully utilized, the state is said to be a perfect 
match. If the technologies themselves are also structurally optimized, then a perfect match is equivalent to a valid technology.

Therefore, technology efficiency can be defined in the following two ways: (1) considering the uniformity of scale, the technical efficiency of manufacturing technology can be measured by its perfectly matched information technology efficiency because the current existence of manufacturing technology is considered to be the most reasonable and most suitable for the needs of enterprise manufacturing. Therefore, information technology efficiency that perfectly matches manufacturing technology is an effective technology, and its technical efficiency is 1. (2) At the stage of manufacturing technology driving information technology, without extending beyond the enterprise, the initial technical efficiency of manufacturing can be expressed as $N_{2}^{0}=1$. Thus, if these two elements are combined, the following definition can be reached.

Definition 3. To begin with, the greater technical efficiency of manufacturing technology and information technology of manufacturing enterprises is equal to 1 .

When the construction stage of integration is transformed into the stage of information technology-driven manufacturing technology, the definition also transforms accordingly.

By definition, the introduction of manufacturing technology efficiency and information technology efficiency is, essentially, another manifestation of the interaction between information technology and manufacturing technology. Manufacturing technology drives the stage of information technology. In essence, manufacturing technology dictates the technical requirements for information technology and promotes the matching of information technology so as to improve the technical efficiency of enterprises. At the stage of information technology promoting manufacturing technology, information technology drives the improvement of manufacturing technology efficiency, and its essence is the process of improving an enterprise's technical efficiency with the power of information technology. This definition will facilitate subsequent discussions on IOITMT.

5.3. Significance Analysis of the Technical Efficiency of IOITMT. There are many related research results pertaining to technical efficiency that can be divided into parametric and nonparametric methods, according to different analysis routes. Parametric methods are widely used in the estimation of technical efficiency [14], where the main idea is represented by a Stochastic Frontier Analysis (SFA) [29]. Nonparametric methods are represented by Data Envelope Analysis (DEA) [30]. Since the technical efficiency of IOITMT of manufacturing enterprises is dynamic, in order to compare this efficiency in a dynamic environment, it is necessary to introduce productivity into the discussion. Productivity is considered to be the basis for calculating technical efficiency. Under static conditions, technical efficiency can be directly obtained by the ratio of actual productivity to optimal productivity. However, when comparing productivity across different periods, there is a problem of the lapsing of the frontier. Discussions of nonparametric methods of productivity have been mostly based on the DEA-Malmquist index method [31], and it is generally recognized that changes in productivity can be decomposed into technical efficiency changes and technological progress [32]. Referring to the production frontier analysis method, supposing time $t$ and time $t+1$ are the two times being considered, time $t$ is taken as the initial time, $M_{0}^{t}$ represents the Malmquist productivity index of decisionmaking units in $t$ time, $\left(x^{t}, y^{t}\right)$ represents the input and output vector of the enterprise at time $t$, and $D_{0}^{t}$ represents the distance function between the actual output and the maximum output based on the technology at time $t$, where the distance function in this paper is the ratio of two kinds of outputs. Therefore, the Malmquist productivity index of taking technology at time $t$ and time $t+1$ as the respective effective technologies can be expressed as

$$
\begin{aligned}
M_{0}^{t} & =\frac{D_{0}^{t}\left(x^{t+1}, y^{t+1}\right)}{D_{0}^{t}\left(x^{t}, y^{t}\right)}, \\
M_{0}^{t+1} & =\frac{D_{0}^{t+1}\left(x^{t+1}, y^{t+1}\right)}{D_{0}^{t+1}\left(x^{t}, y^{t}\right)} .
\end{aligned}
$$

The Malmquist productivity index denotes the change ratio of technical efficiency. According to the Fisher ideal decomposition method [33], the geometric mean of the two exponents is used as a measure of productivity change:

$$
\begin{aligned}
M_{0}^{t+1}\left(x^{t+1}, y^{t+1}, x^{t}, y^{t}\right) & =\left(M_{0}^{t} \cdot M_{0}^{t+1}\right)^{(1 / 2)} \\
& =\left(\frac{D_{0}^{t}\left(x^{t+1}, y^{t+1}\right)}{D_{0}^{t}\left(x^{t}, y^{t}\right)} \cdot \frac{D_{0}^{t+1}\left(x^{t+1}, y^{t+1}\right)}{D_{0}^{t+1}\left(x^{t}, y^{t}\right)}\right)^{(1 / 2)} .
\end{aligned}
$$

Assuming constant returns to scale, the Malmquist productivity index can be decomposed into the product of two factors:

$$
\begin{gathered}
M_{0}^{t+1}\left(x^{t+1}, y^{t+1}, x^{t}, y^{t}\right)=\frac{D_{0}^{t+1}\left(x^{t+1}, y^{t+1}\right)}{D_{0}^{t}\left(x^{t}, y^{t}\right)} \\
\cdot\left(\frac{D_{0}^{t}\left(x^{t+1}, y^{t+1}\right)}{D_{0}^{t+1}\left(x^{t+1}, y^{t+1}\right)} \cdot \frac{D_{0}^{t}\left(x^{t}, y^{t}\right)}{D_{0}^{t+1}\left(x^{t}, y^{t}\right)}\right)^{(1 / 2)} .
\end{gathered}
$$

The first factor is the ratio of the technical efficiency of two kinds of technologies corresponding to two moments, which is the change index of pure technical efficiency. The second factor is the technology change index relative to the two efficient technologies.

In order to understand this decomposition method more clearly and in light of the current research topic, it is assumed that when both input and output are a type of element, the return to scale remains unchanged. The decomposition mode is shown in Figure 7.

The input and output of a manufacturing enterprise is $E_{0}$ at time $t$, when corresponding to the actual output is $Q_{0}$; the input is $E_{1}$ at time $t+1$, and the actual output is $Q_{1}$. The output rate moves from $O A$ to $O B$ in two moments of time, 


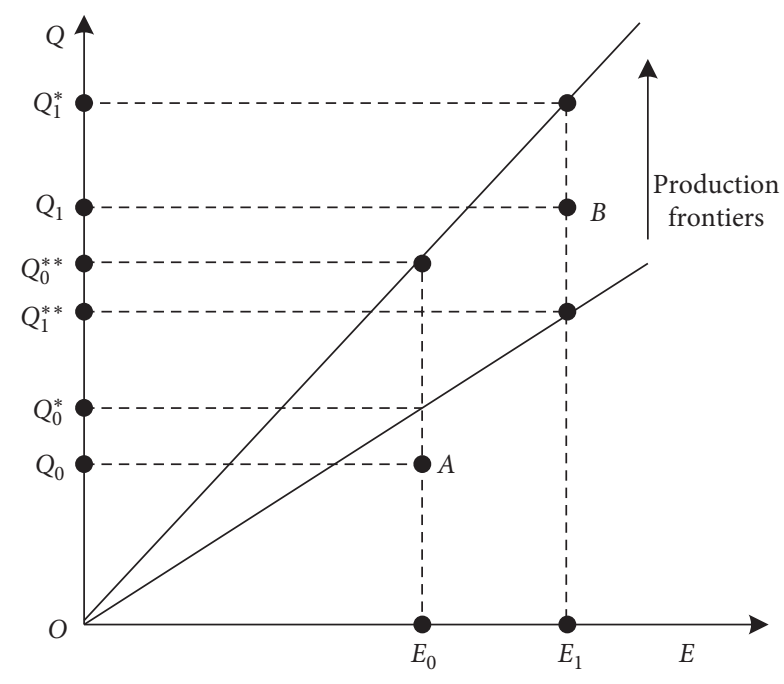

FIgURE 7: Decomposition of productivity index.

and the production frontier moves from bottom to top due to technological progress. The Malmquist productivity indexes of taking technology at time $t$ and time $t+1$ as the respective effective technologies are as follows:

$$
\begin{aligned}
M_{0}^{t} & =\frac{Q_{1} / Q_{1}^{* *}}{Q_{0} / Q_{0}^{*}}, \\
M_{0}^{t+1} & =\frac{Q_{1} / Q_{1}^{*}}{Q_{0} / Q_{0}^{* *}} .
\end{aligned}
$$

The Malmquist productivity index is broken down into

$$
\begin{aligned}
M_{0}^{t+1}(O B, O A) & =\frac{Q_{1} / Q_{1}^{*}}{Q_{0} / Q_{0}^{*}} \cdot\left(\frac{Q_{1} / Q_{1}^{* *}}{Q_{1} / Q_{1}^{*}} \cdot \frac{Q_{0} / Q_{0}^{*}}{Q_{0} / Q_{0}^{* *}}\right)^{(1 / 2)} \\
& =\frac{Q_{1} / Q_{1}^{*}}{Q_{0} / Q_{0}^{*}} \cdot\left(\frac{Q_{1}^{*}}{Q_{1}^{* *}} \cdot \frac{Q_{0}^{* *}}{Q_{0}^{*}}\right)^{(1 / 2)} \cdot
\end{aligned}
$$

From equation (5), it can be seen that the first term is the change rate of pure technical efficiency and the second term is the rate of technical progress caused by the change of frontier. On the one hand, productivity change is the change in pure technical efficiency. On the other hand, this is caused by technological progress.

In summary, in the case of the fixed scale effect, when comparing the technical efficiency of manufacturing enterprises in different periods, this cannot be measured by a single frontier. Rather, the change in technical efficiency and technological progress should be comprehensively considered.

\section{Self-Organizing Evolution Model of the Technological Efficiency of IOITMT}

6.1. Establishing the Model. Manufacturing technology efficiency and information technology efficiency measure the ratio between an enterprise's actual and maximum output under the same input of production factors from different angles, and they more vividly represent the enterprise's technological manufacturing and information levels under the current established external technical environment. Generally, with the expansion and deepening of integration, information technology and manufacturing technology will promote each other, and technical efficiency will change.

While the construction of IOITMT is influenced by the external, it will not affect the internal structure of the enterprise. Instead, IOITMT is implemented through the internal behavior of the enterprise. IOITMT of manufacturing enterprises is self-organized. In a single period, as with technology, it is reasonable to analyze the internal informatization and industrialization of enterprises independently based on the self-organization characteristics of IOITMT, when technology introduced from the outside is not taken into account or does not cause a technical change. The interaction between information technology and manufacturing technology can be expressed as the following model:

$$
\left\{\begin{array}{l}
\dot{N}_{1}=f_{1}\left(N_{1}, N_{2}\right), \\
\dot{N}_{2}=f_{2}\left(N_{1}, N_{2}\right),
\end{array}\right.
$$

where $f_{i}\left(N_{1}, N_{2}\right)$ denotes the coupling function of manufacturing technology and information technology and $f_{1}\left(N_{1}, N_{2}\right)$ and $f_{2}\left(N_{1}, N_{2}\right)$, respectively, represent the development speed of information technology efficiency and manufacturing technology efficiency. Hence, $\left(\partial f_{1}\left(N_{1}\right.\right.$, $\left.N_{2}\right) / \partial N_{2}$ ) represents the influence of manufacturing technology efficiency on the development speed of information technology efficiency, and $\left(\partial f_{2}\left(N_{1}, N_{2}\right) / \partial N_{1}\right)$ represents the influence of information technology efficiency on the development speed of manufacturing technology efficiency.

6.2. Analysis of the Self-Organizing Evolution Model of the Technology Efficiency in IOITMT. As mentioned earlier, the technical efficiency increment is calculated by the productivity. When the effect of scale is neglected, the change in productivity is composed of the external technological progress and the change in pure technical efficiency. With this in mind, how does technology change within an enterprise? The discussion on this issue is directly related to the following research content.

On the one hand, information technology and manufacturing technology match. On the other hand, information technology and manufacturing technology promote each other; the penetration of information technology promotes manufacturing technology, and the development of manufacturing technology promotes the improvement and progress of information technology. Therefore, in light of the focus of the current paper, IOITMT can be analyzed from two perspectives: integration and technological progress within the process of integration. According to the dynamic promotion model analysis of the integration technology of manufacturing enterprises, the latter's internal technological change is affected by both internal and external functions. To distinguish between different types of technological progress, a distinction needs to be made according to the source. The improved level of technology 
induced by the enterprises' internal role is termed the progress of fusion technology, that is, the improvement of technology caused by the integration of manufacturing technology and information technology. The internal technological change caused by an enterprise's external environment is called the introduction technology progress, which refers to the internal technology improvement caused by the introduction of external technology.

Based on the theme of integration, the current paper focuses on the progress of integration technology. There are different ways to discuss different technological progress. There is the manufacturing-technology-promoting-information-technology stage. In practice, the updating of both information and manufacturing technology require capital investment and R\&D time. On the one hand, the implementation of informatization in manufacturing enterprises is a gradual process, and the application and development of information technology are mainly subject to the requirements of manufacturing technology, which basically involves the point-to-point implementation of informatization. In this stage, at the beginning of the smooth application of reasonably new information technology, a period of time is necessary in order to achieve the perfection of the technology's initial operation and systematization, and the development speed of information technology efficiency will be gradually improved after this process. According to the aforementioned analysis, the enterprise's comprehensive technical efficiency is equal to the information technology efficiency, and thus, the performance of the enterprise also increases accordingly. With the integration of information technology, the enterprise will continue to develop steadily for a period of time. With the saturation of the technology utilization space, the gap between manufacturing technology and information technology in terms of technical efficiency will continue to shrink, and the promotion effect of manufacturing technology on information technology will gradually weaken as the gap decreases. Therefore, based on the technical efficiency definition given earlier, the initial manufacturing technical efficiency is 1 . Under the guidance of manufacturing technical efficiency, information technology efficiency $N_{1}$ will, in general, gradually increase, and the lifting effect will gradually decrease. Therefore, at this stage, the following can be assumed.

Hypothesis 1. The promotional effect of manufacturing technology efficiency on the development speed of information technology efficiency first increases and then decreases.

Under normal operating conditions, $\dot{N}_{1} \geq 0$. If the fact that the enterprise is introducing technological advances is not taken into account, information technology efficiency $N_{1}$ can exert changes only by the efficiency of the manufacturing technology. Thus, it can be assumed that $\left(\partial f_{1}\left(N_{1}, N_{2}\right) / \partial N_{1}\right)=0$. By definition, information technology efficiency $N_{1}$ is a short board of a barrel. It is the embodiment of manufacturing enterprises' comprehensive technical efficiency, from which it can be concluded that the change trajectory of the comprehensive technical efficiency conforms to the logistic equation.

\subsubsection{Statement}

(1) It is not excluded that an unreasonable IOITMT has been implemented in the early stage, laying the foundation for a growth model that may rapidly deteriorate without the occurrence of the said situation. Here, only the smooth implementation model is discussed.

(2) This paper consistently considers "introducing technological advances" separately throughout the discussion. In fact, an evolutionary cycle is considered from the perspective of integration, which is exactly the purpose of this paper. In other words, the focus is on the "technology integration progress" brought by the IOITMT, where this progress is taken as an important symbol of division in the cycle.

(3) Considering that "integration" is the research topic of this paper, the main indicators for dividing the discussion cycles are a relatively large amount of introduction technology progress, a relatively large amount of investment scale changes, and systemic updates caused by business changes.

6.3. Order Parameter Analysis of Technology Efficiency Model in IOITMT. As the core principle of synergetic theory, the slaving principle focuses on the decisive effect of order parameters in forming a system's structure; therefore, the determination of order parameters is an inevitable research topic within the problem of self-organization. The acquisition of system order parameters can help manufacturing enterprises determine the current key factors, grasp the key points of construction and the direction of construction, and acquire practical guiding value for IOITMT of manufacturing enterprises. In different development stages, the interaction between information technology and manufacturing technology changes dynamically, and the order parameters are also different. This paper adopts the method of order parameter qualitative analysis. In the stage of manufacturing technology promoting information technology, the information technology efficiency directly determines the integration quality of IOITMT. Therefore, information technology efficiency is taken as the order parameter in this stage.

The same analysis is applicable to the phase of information technology promoting manufacturing technology. Manufacturing technology efficiency becomes a new order parameter. When the improvement effect of manufacturing technology efficiency on information technology efficiency disappears, IOITMT enters the phase of stalemate. While, at this point, the two still promote and restrict each other, and it is difficult to distinguish the primary from the secondary, meaning that there is no order parameter. When a certain technology breaks through the deadlock, gains technical progress, or manifests significant obstacles to development, IOITMT will enter the next stage. Given that order parameter servitude makes the system evolve, how does IOITMT of an enterprise evolve in three stages? In the following part of this paper, this issue is further 
discussed in order to provide valuable guidance for enterprises' IOITMT.

\section{Technical Convergence Evolutions under Order Parameter Servitude}

Enterprises' manufacturing and information technology do not exist independently but remain dependent. Integration is not a simple superposition of technologies but, rather, interplay of infiltration and interaction. IOITMT is the superposition evolution process of the interaction between industrialization and informatization. This paper studies the three stages of the self-organized evolution of the interaction between manufacturing technology and information technology, from the perspective of technology convergence.

Convergence originates from the mathematical discipline referring to a point moving towards some value. In the 1980s, since Abramovitz [34] and Baumol and Wolff [35] introduced convergence into the field of economics, convergence theory has received much attention. The original purpose of studying convergence theory was to test a hypothesis proposed by neoclassical economic growth: the assumption of the relationship between the rate of economic growth and the initial level. Economic growth theory holds that "convergence" indicates that the income gap between countries or regions is decreasing and that the economic growth rate of an economy is positively correlated with the distance between the economic state and the stable state, which is also the basic assumption of the neoclassical economic growth model.

According to the theory of convergence [36], convergence can be classified, from different perspectives, as follows: (1) according to the element attribute of convergence, it can be divided into homogeneous convergence and heterogeneous convergence. The convergence of elements with the same attributes is homogeneous convergence; otherwise, it is heterogeneous convergence. (2) According to the convergent scope of elements, it can be divided into conditional convergence and unconditional convergence. Convergence that is restricted in the given scope is called conditional convergence, and that with unconditional constraint is termed unconditional convergence. (3) According to different speeds, convergence can be divided into symmetric and asymmetric convergence. The same speed of convergence reflects symmetric convergence, while different speeds denote asymmetric convergence. (4) According to direction, convergence can be divided into "consistent convergence" and "counterpropagating convergence." This can be compared to the "convergence" and "divergence" found in economic growth theory. (5) Finally, there is game convergence, which can be divided into one convergence or multiple convergences according to the characteristics of the game.

Based on this research idea, the current paper discusses the internal convergence of IOITMT. According to the aforementioned definition of manufacturing technical efficiency and information technology efficiency, this paper further develops a research system of convergence evolution in terms of both theory and method and discusses the construction path and quality of integration under uncertain parameters. In order to distinguish the results before and after integration, the following definitions are introduced, in line with the technical efficiency studied in this paper.

Definition 4. Multiple established technologies are integrated with one another. If there is at least one technology that cannot be fully utilized due to short board technology, this state is called matching.

Matching is, clearly, the result of integration under the current unbalanced technology condition and is the comprehensive technology state with existing technology waste. Moving from matching to perfect matching is also a process of minimizing technology waste.

The advantages of defining "match" and "perfect match" are obvious. First, on the same scale, a two-dimensional convergence problem is simplified to one-dimensional convergence, which will shortly be proved mathematically, and the conclusion of which can be extended to a higherdimensional heterogeneous convergence problem. Second, convergence is the essence of convergence and reflects the pursuit of low performance to high performance and high performance to low performance in order to release the energy process. Third, the ideal outcome of convergence (IOITMT) under a given technology is all matching, which means that the technical efficiency of manufacturing technology will match that of information technology in the IOITMT.

From this discussion, the conclusion can be drawn that the discussion of heterogeneous convergence can be unified in terms of the attributes after the introduction of "perfect matching" and "matching." It is important to highlight the connection and distinction between matching, perfect matching, and effective techniques. Firstly, "matching" is the limit state of technological convergence under the current situation of multiple unbalanced technologies: a state of technological waste. A "perfect match" is the limit state of convergence under equilibrium technology or the limit of convergence with the development of dynamic equilibrium technology. "Effective technology" reflects the highest ideal, under the premise of perfect matching; if the internal structure of the technology is optimized, the technology is effective. The perfect matching studied in this paper is the state of dynamic change in the process of convergence, whereby the gradual upgrade of the matching state must be accompanied by the optimization of the technical internal structure configuration. Thus, the dynamic "perfect match" is equivalent to "effective technology." In the later convergent analysis, the assumption is made that "perfect matching" means "effective technology." This is completely consistent with the above definition of manufacturing technical efficiency.

7.1. The Essence of Convergence Technology in IOITMT. In combination with this analysis, manufacturing technology and information technology permeate each other in the process of IOITMT to improve the comprehensive technical 
efficiency, with the same expected goal and direction. Therefore, information technology and manufacturing technology can be seen as forming consistent convergence. In this paper, manufacturing technology and information technology are analyzed as two technologies. In view of the difference between information technology and manufacturing technology, the convergence of information technology and manufacturing technology can be seen as a two-dimensional heterogeneous convergence.

Based on the characteristics of IOITMT, this paper first studies the evolution process of two-dimensional heterogeneous convergence under different convergence parameters, theoretically and methodologically.

By definition, the initial technical efficiency of manufacturing technology is that of information technology efficiency that is perfectly matched with manufacturing technology. Therefore, motivated by manufacturing technology, information technology converges to the target information technology. Although manufacturing technology and the ideal information technology are perfectly matched, based on the current situation of information technology, manufacturing technology can only actively converge to the current technology or be "consumed" passively, thus reducing the technical efficiency of manufacturing technology. If $N_{1}^{(0)}=a$ and $N_{2}^{(0)}=b$ represent the information technology efficiency and manufacturing technology efficiency at $t_{0}$, and if $a<b$ is satisfied, this indicates that the manufacturing technical efficiency is higher than the information technology efficiency. According to the aforementioned analysis, at the beginning of the convergence cycle, $b=1$.

The convergence of efficiency in the process of IOITMT is not achieved overnight. Instead, it is adjusted step-by-step with reference to the technological gap. The pace and speed of adjustment are affected by many aspects, thus forming the so-called multiround convergence. According to the natural law of the power to release energy from high energy to low energy, the development of economic and social systems always pursues the improvement of efficiency. Therefore, the elements with low technical efficiency tend to be the elements with high efficiency and, with the approach of elements, the pace of element convergence will gradually slow down.

Based hereon, the one-dimensional perspective of technical efficiency is discussed, as shown in Figure 8.

The definition of technical efficiency in this paper renders the information technology and manufacturing technology equivalent under the unified technical efficiency coordinate. As shown in Figure 8, the projection of $B$ on the horizontal axis represents the information technology that perfectly matches the current initial manufacturing technology. According to the definition of technical efficiency and the definition of perfect matching, the perfectly matched information technology efficiency is equal to the manufacturing technology efficiency. As shown in Figure 9, the projection of $A$ on the vertical axis denotes the technical efficiency of the manufacturing technology matching the current initial information technology. Points $A$ and $B$ represent an exact match between the current information technology and the current manufacturing technology: point

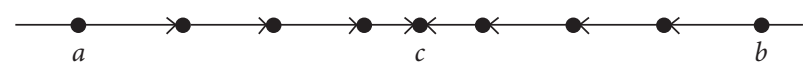

Figure 8: One-dimensional convergence of technical efficiency.

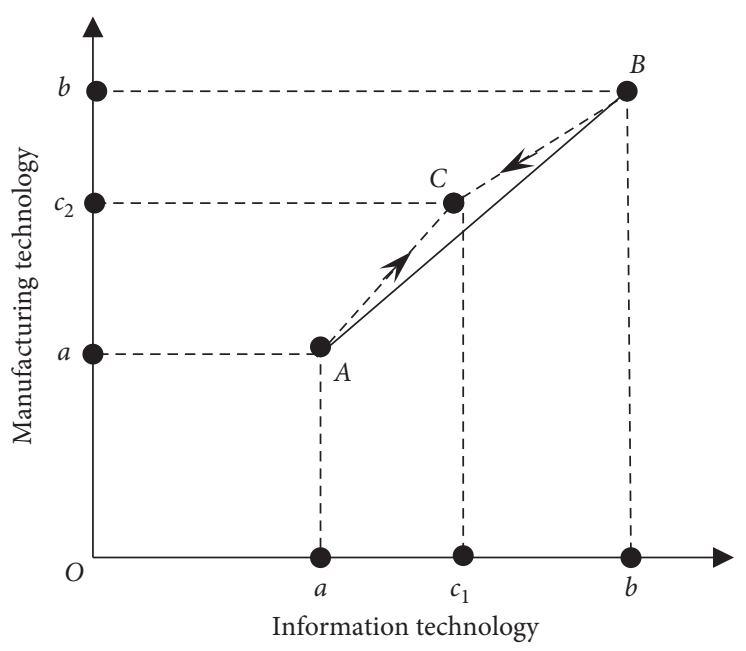

FIgure 9: Two-dimensional heterogeneous convergence model of technical efficiency.

$A$ to point $B$ on the linear $y=x$. The process of IOITMT is such that information technology and manufacturing technology approach each other with their convergence parameters; information technology improves in the application of manufacturing technology, and manufacturing technology improves in the application of information technology. Specifically, information technology on the vertical axis falls under the attraction of manufacturing technology from $a$ to $b$ and manufacturing technology on the horizontal axis under the attraction of information technology from $b$ to $a$. The comprehensive performance eventually approaches point $C$, and the actual coordinates are $\left(c_{1}, c_{2}\right)$.

In the discussion of one-dimensional convergence, it was pointed out that the equivalent expression of element convergence is such that the elements eventually tend towards the same point. This, then, inspires the question: can two-dimensional convergence necessarily converge to the same point? Can one-dimensional and two-dimensional convergences be completely unified? How do different convergence parameters affect convergence? These issues are discussed in the model and analysis.

7.2. Technical Convergence Model. This model is used to discuss the convergence of manufacturing technology to promote the information technology stage, and the analysis is conducted in this stage by default, unless otherwise specified. Here, the conclusion can be drawn that information technology drives industrial technology.

7.2.1. Model Assumptions. When considering manufacturing technology factors and information technology factors, the influence of human, management, and other factors 
internal to manufacturing enterprises cannot be ignored. This paper does not deliberately avoid them. Rather, in order to facilitate the discussion, the influence of other factors is mapped onto convergence parameters. Of course, the necessary model assumptions are indispensable.

First, the ideal technology convergence environment is discussed. Although external technological progress is constantly ongoing, the internal technology of an enterprise cannot be constantly updated. There still exists a long or short period in which the enterprise does not introduce technological progress. Therefore, the following hypotheses are proposed.

Hypothesis 2. There is no introduction technological progress in a convergence cycle of the discussion of enterprise technical efficiency. For the purposes of this paper, a convergence cycle refers to the movement from the beginning of the convergence to the end of the convergence, essentially the run-in period of a given technology. Hypothesis 2 guarantees that, within the discussion scope of a convergence cycle, technical efficiency change is not caused by the introduction of technological progress but is the result of integration. That is to say, the change in information technology efficiency within a convergence cycle is caused by the internal cause of its convergence to manufacturing technology efficiency, rather than the advance of the frontier, and is not affected by the change in factor input. Of course, it is necessary to discuss the trend across the cycle and, at the same time, to introduce technological progress.

Considering the technical convergence, the additional input of other factors will further complicate the performance analysis of convergence due to the scale effect. Based on basic modelling assumptions, the same analysis method as that applied to technical progress was adopted. There will always be a long or short period of time. The convergence of elements is only a change in the configuration of elements, without an increase in their scale.

Hypothesis 3. There is no change of factor scale or significant change in a convergence cycle of the discussion of an enterprise's technical efficiency.

The assumption of constant factor size guarantees the comparability of the beginning and end states of a convergence cycle. Of course, the more general situation will be an important aspect of the follow-up study.

Combining Hypotheses 2 and 3, the beginning of a cycle should be marked by significant changes in factor scale and the introduction of technological progress. This also provides a method through which to divide the cycle in order to analyze the integration problem. As mentioned, the convergence of the two elements is not achieved overnight, and there can be many moments of convergence within a convergence cycle. Therefore, it is worth paying attention to the speed of element convergence. Lottes introduced the coefficient of convergence to represent the influence of factors, arguing that the convergent speed of factors with great influence is low and that this coefficient can be used to measure the convergent speed of factors. The current paper provides a further in-depth analysis of this point of view and, in the process of factor convergence, eliminates redundant cost differences: when the gap between the factors is larger, the promotion of low-energy factors will be easier, and the promotion intensity will be greater. Conversely, when the distance between factors is gradually narrowed, the difficulty of improving will increase, and the intensity of improving will also be reduced. Based on the simplest hypothesis, it can be assumed that the rate of convergence of a factor is directly proportional to the degree of difference between this factor and other factors, namely,

$$
\Delta N_{i}^{k}=r_{i}^{k} d\left(N_{i}^{k-1}\right)
$$

Therefore, the convergence parameter can be expressed as

$$
r_{i}^{k}=\frac{\Delta N_{i}^{k}}{d\left(N_{i}^{k-1}\right)},
$$

where $\Delta N_{i}^{k}$ represents the variation of factor $N_{i}$ in time $k, d\left(N_{i}^{k-1}\right)$ represents the distance between factors $N_{i}$ with others in time $k-1$, and $r_{i}^{k}$ is the convergence coefficient. Clearly, $r_{i}^{k}$ is the ratio of the increment to the distance. In practical terms, $r_{i}^{k}$ is an indeterminate variable. The current paper takes the mean of that variable and considers it as constant. That is to say, the variation $\Delta N_{i}^{k}$ of factors $N_{i}$ in time $k-1$ is proportional to the distance of factors $d\left(N_{i}\right)$ in arbitrary moment $k$ :

$$
r_{i}=\frac{\Delta N_{i}^{k}}{d\left(N_{i}^{k-1}\right)} .
$$

Hypothesis 4. The convergence speed of the factor is proportional to the degree of difference between the factor and other factors.

Key conclusions can be drawn from equation (9). $r_{i}$ is the variation of distance between the factors. On the one hand, the variation of factors is related to the technological basis and technological environment of the factors themselves. On the other hand, this variation greatly depends on subjective factors such as manpower input and management strength. Therefore, regulating the convergence coefficient is expected to control the convergence outcome effectively.

$r_{1}$ and $r_{2}$ are the convergence parameters of information technology and manufacturing technology. The convergence process of IOITMT is affected by other factors, which are all included in the convergence parameters. IOITMT is a gradual process, whereby manufacturing and information technology permeate one other, and integration has a certain continuity and gradual progress. Therefore, the following convergence parameters can be considered: $0<r_{1}, r_{2} \ll 1$.

7.2.2. Model Construction. The convergence of information technology and manufacturing technology can be modeled according to the dynamic change of technical efficiency. Expanding equation (9) and supposing that, after $k$ rounds of convergence, at this point in time, information technology efficiency and manufacturing technology efficiency should conform to the following convergence model: 


$$
\begin{aligned}
& N_{1}^{(k)}=N_{1}^{(k-1)}+r_{1}\left(N_{2}^{(k-1)}-N_{1}^{(k-1)}\right), \\
& N_{2}^{(k)}=N_{2}^{(k-1)}+r_{2}\left(N_{1}^{(k-1)}-N_{2}^{(k-1)}\right) .
\end{aligned}
$$

Here, the distance between factors is considered to be the difference between technical efficiency. It can be seen that the convergence model constructed by technical efficiency is equivalent to the one-dimensional convergence model in terms of form, which greatly simplifies the subsequent derivation and calculation.

The following presents an analysis of the final convergence state. Supposing that after $m$ rounds of convergence, the technical efficiency state converges to $N_{1}^{(m)}$ and $N_{2}^{(m)}$. If $N_{1}^{(m)}<N_{2}^{(m)}$, the gap will lead to the next round of convergence, and evolution will occur according to (10) and (11). If $N_{1}^{(m)}>N_{2}^{(m)}$, similarly, the optimization ability of convergence will drive the convergence of manufacturing technology and information technology in the opposite direction of (10) and (11). From this analysis, it can be concluded that the ideal state of final convergence will be the matching state $N_{1}^{(m)}=N_{2}^{(m)}$. Of course, this conclusion is related to the specific definition of information technology efficiency constructed for the purposes of this paper: the conclusion that tends to the same level of technical efficiency makes the two-dimensional heterogeneous convergence here equivalent to the one-dimensional convergence in terms of form and mathematical derivation. This is, clearly, also an important aspect of the model's validation.

Therefore, factor convergence and factor convergence to the same point can be equivalent, which is consistent with the definition of homogeneous convergence proposed by Durlauf and Johnson [37]. Thus, the convergence point satisfies $c=c_{1}=c_{2}$, termed the fusion technology efficiency. It also refers to the aforementioned enterprise comprehensive technical efficiency.

This conclusion will now be proven and the validity of the model verified. First, Equations (10) and (11) can be further summarized as

$$
\begin{aligned}
& N_{1}^{(k)}=\left(1-r_{1}\right) N_{1}^{(k-1)}+r_{1} N_{2}^{(k-1)}, \\
& N_{2}^{(k)}=r_{2} N_{1}^{(k-1)}+\left(1-r_{2}\right) N_{2}^{(k-1)},
\end{aligned}
$$

and denoted as

$$
\left(\begin{array}{c}
N_{1}^{(k)} \\
N_{2}^{(k)}
\end{array}\right)=\left(\begin{array}{cc}
1-r_{1} & r_{1} \\
r_{2} & 1-r_{2}
\end{array}\right)\left(\begin{array}{c}
N_{1}^{(k-1)} \\
N_{2}^{(k-1)}
\end{array}\right) .
$$

Taking the technology efficiency state vector $N=\left(N_{1} / N_{2}\right)$ and the state-transition matrix $A=\left(\begin{array}{cc}1-r_{1} & r_{1} \\ r_{2} & 1-r_{2}\end{array}\right)$ and $N^{(0)}=\left(\begin{array}{c}a \\ b\end{array}\right)$, the above equation can be further expressed as a constant difference equation:

$$
N^{(k)}=A N^{(k-1)} \text {. }
$$

The analogy follows that

$$
N^{(k)}=A N^{(k-1)}=A^{2} N^{(k-2)}=\cdots=A^{k} N^{(0)} .
$$

By solving the characteristic root of matrix $\mathrm{A}$, where $|\lambda I-A|=0$, when $r_{1}+r_{2} \neq 1$, two characteristic roots of matrix A are obtained: $\lambda_{1}=1, \lambda_{2}=1-r_{1}-r_{2}$. The corresponding eigenvector is

$$
\begin{aligned}
& P_{1}=\left(\begin{array}{l}
1 \\
1
\end{array}\right), \\
& P_{2}=\left(\begin{array}{c}
r_{1} \\
-r_{2}
\end{array}\right) .
\end{aligned}
$$

Denoted as the matrix $P=\left(P_{1}, P_{2}\right)$, the following can be obtained:

$$
P^{-1}=\frac{1}{r_{1}+r_{2}}\left(\begin{array}{cc}
r_{2} & r_{1} \\
1 & -1
\end{array}\right) \text {. }
$$

Jordan form of matrix $A$ is

$$
A=P J P^{-1} \text {, }
$$

where $J=\left(\begin{array}{cc}1 & 0 \\ 0 & 1-r_{1}-r_{2}\end{array}\right)$. Combining equations (15) and
(18) gives

$$
\begin{aligned}
N^{(k)} & =P J^{k} P^{-1} N^{(0)} \\
& =\frac{1}{r_{1}+r_{2}}\left(\begin{array}{c}
r_{2} a+r_{1} b+(a-b) r_{1}\left(1-r_{1}-r_{2}\right)^{k} \\
r_{2} a+r_{1} b-(a-b) r_{2}\left(1-r_{1}-r_{2}\right)^{k}
\end{array}\right) .
\end{aligned}
$$

Then, due to $0<r_{1}, r_{2} \ll 1$, it is possible to obtain

$$
\lim _{k \rightarrow \infty} N^{(k)}=\left(\begin{array}{c}
\frac{r_{2} a+r_{1} b}{r_{1}+r_{2}} \\
\frac{r_{2} a+r_{1} b}{r_{1}+r_{2}}
\end{array}\right) .
$$

After multiple rounds of convergence, the limit state of $N_{1}$ and $N_{2}$ tends towards the same value; that is, manufacturing technology factors and information technology factors form convergence points in terms of technical efficiency. Convergence point $C$ in Figure 8 should lie on the line between points $A$ and $B$, and the convergence mode in Figure 9 is the same as that in Figure 10. This conclusion is not special and can be easily extended to the problem of high-dimensional heterogeneous convergence.

7.2.3. Model Analysis. It should be noted that the convergence from low to high efficiency is easier to feel intuitively, while the convergence from high to low efficiency can be experienced from two perspectives: (1) since the comprehensive technical efficiency represented by information technology efficiency is low, the manufacturing technical efficiency cannot be fully exerted or the objective technical efficiency will be lost when the manufacturing technical efficiency tilts towards it. (2) For the purpose of coordinated and balanced development, the overall performance of 


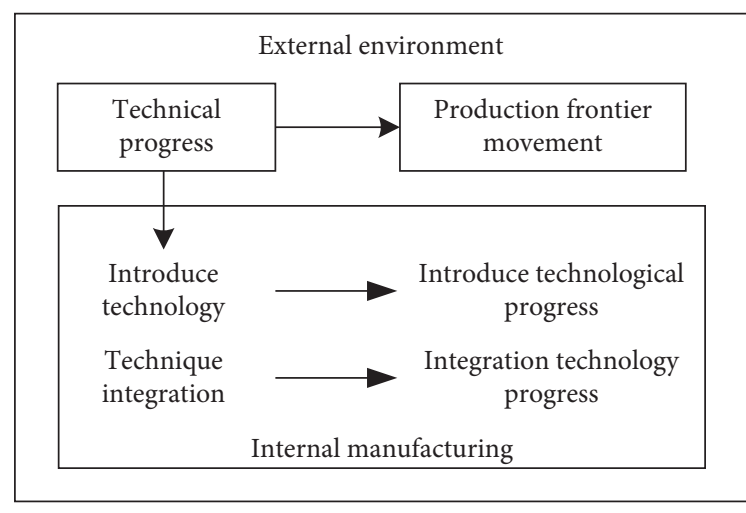

FIGURE 10: Connotation analysis of the IOITI of manufacturing enterprises.

integration technology efficiency is improved by drawing closer to information technology through manufacturing technology. Therefore, the values of $r_{1}$ and $r_{2}$ are affected by the thinking of decision makers.

Without considering the external technical progress and the internal introduction technical progress and following the definition of technical efficiency provided earlier, by combining $a<b \leq 1$, the ideal output $Q_{\text {ideal }}$ corresponding to the integration technical efficiency can be calculated, as follows:

$$
\begin{gathered}
Q_{\text {ideal }}=\left(\frac{r_{2} a+r_{1} b}{r_{1}+r_{2}}\right) \cdot Q^{*}<Q^{*}, \\
\text { or }_{\text {ideal }}=\left(\frac{r_{1}(b / a)+r_{2}}{r_{1}+r_{2}}\right) \cdot Q_{0}>Q_{0} .
\end{gathered}
$$

Conclusion 1. The integration of technology efficiency lies between manufacturing technology efficiency and information technology efficiency in the initial state.

After the convergence of IOITMT, information technology efficiency improves, while manufacturing technology efficiency experiences a loss, thus not being completely matched. The technical efficiency integration can be further sorted as

$$
c=\frac{r_{2} a+r_{1} b}{r_{1}+r_{2}}=\frac{r_{2} a+r_{1} a-r_{1} a+r_{1} b}{r_{1}+r_{2}}=a+\frac{b-a}{1+\left(r_{2} / r_{1}\right)} .
$$

Conclusion 2. The integration of the technology efficiency value depends on the ratio of $\left(r_{1} / r_{2}\right)$; the smaller the ratio, the lower the integration of technology efficiency.

The convergence parameter represents the change in factors under the unit factor distance. Therefore, in the IOITMT stage of industrialization to promote informatization, the influence ratio of manufacturing technology as an order parameter is greater than that of information technology. Moreover, the closer to the initial manufacturing technology efficiency $b$, the higher the integration of technology efficiency. The regulatory ratio of influence factors and the strength of convergence become key to improving the integration of technology efficiency (Figure 11).

Furthermore, equation (22) can be changed to

$$
\frac{r_{1}}{r_{2}}=\frac{c-a}{b-c} .
$$

Thus, a result is obtained parallel to Conclusion 2 .

Conclusion 3. Ratio $\left(r_{1} / r_{2}\right)$ shows the segmentation of the initial manufacturing technology efficiency and the initial information technology efficiency by the integration of technology efficiency.

Furthermore, according to the definition of technical efficiency,

$$
\frac{r_{1}}{r_{2}}=\frac{\left(\Delta N_{1}^{k} / d\left(N_{1}^{k-1}\right)\right)}{\left(\Delta N_{2}^{k} / d\left(N_{2}^{k-1}\right)\right)}=\frac{\Delta N_{1}^{k}}{\Delta N_{2}^{k}}
$$

Conclusion 4. Increasing efforts to develop low-efficiency technologies, and improving the variation of low technical efficiency in each round of convergence, will affect the final convergence of technical efficiency. The interesting aspect of this conclusion is that, in the convergent limit state, manufacturing technology matches information technology. By considering the discrete time system given by the difference in equation (14) and placing convergence point $N^{(k-1)}$ into equation (18), $N^{(k)}=N^{(k-1)}$ can be obtained. Therefore, the point of convergence is the equilibrium point.

Furthermore, it is possible to prove that the equation only has a nonzero equilibrium point of convergence; the convergence will only go to this state. Equation (14) can be completed as

$$
N^{(k)}-N^{(k-1)}=A N^{(k-1)}-N^{(k-1)}=(A-I) N^{(k-1)} .
$$

The equilibrium point of IOITMT system is satisfied by $N^{(k)}=N^{(k-1)}$, namely, $(A-I) N^{(k-1)}=0$, so a sufficient condition for the existence of a nonzero equilibrium is that the matrix $(A-I)$ be singular, that is,

$$
|A-I|=\left|\begin{array}{cc}
1-r_{1}-1 & r_{1} \\
r_{2} & 1-r_{2}-1
\end{array}\right|=0 .
$$

Therefore, IOITMT system (14) has only one nonzero equilibrium point, and the rank of the matrix is 1 . This means that when technical efficiency reaches its limit, manufacturing technology and information technology reach a stalemate. In other words, IOITMT goes into the second stage, where the technical efficiency of each has exhausted its ability to promote one another, and there is interaction only in terms of minor adjustments.

In this stalemate stage, IOITMT system develops harmoniously, while the aforementioned convergence model is unable to break through the situation. It is only when the information (manufacturing) technology absorbs more 


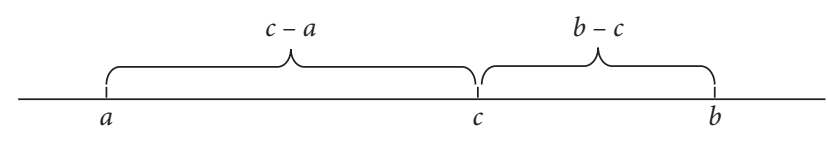

FIGURE 11: Relationship between the position of technology efficiency of IOITMT and convergence parameters.

energy from the external environment in order to improve its own technical efficiency in integration, and the new integration mode begins and enters the third stage of IOITMT. For example, manufacturing technology innovations include the introduction of new manufacturing technology, business process optimization and adjustment, and manufacturing mode upgrading, while information technology innovations include the introduction of advanced information technology and intelligent technology upgrading. The integration of the third stage is similar to that of the first stage. Of course, the diversity and randomness of practical problems cannot be excluded. Only theoretical models are discussed here.

7.2.4. Convergence Model considering Uncertain Convergence Parameters. The results pertaining to the ideal conditions are, clearly, not entirely satisfactory. In reality, IOITMT cannot be so smoothly integrated into the optimum state. The reason for this is that, under the ideal state mentioned previously, the model assumes that the convergence parameters are certain. However, in practical scenarios, IOITMT is affected not only by deterministic factors but also by various uncertain factors. For example, the quality of management, the leadership concept, the structure of the enterprise, the degree of technological fit, and the interference and random factors of the internal and external environments all comprise such uncertainties, which will inevitably lead to the positive or negative deviation between the actual integration and the ideal conclusion. The resulting additional benefits or opportunity costs are referred to as coordination benefits or deviation costs in order to demonstrate the effectiveness of integration.

(1) Convergence Model under the Uncertainty of Uniform Distribution. The progressive nature of the evolution of convergence is the optimal choice of convergence. Therefore, the state transfer mode of technical efficiency is not affected by uncertainty. Uncertainty manifests itself by changing the convergence parameters. For the sake of convenience, it is posited that uncertainty is evenly distributed in the convergence parameters corresponding to discrete time, and the following hypotheses are proposed.

Hypothesis 5. Uncertainty factors of the convergence of manufacturing technology and information technology affect the evolution of IOITMT system through the convergence parameters of convergence.

Hypothesis 6. Uncertainty is independent of time.

Based on the above analysis, Models (10) and (11) can be extended to

$$
\begin{aligned}
& N_{1}^{(k)}=\left(1-r_{1}-\Delta r_{1}\right) N_{1}^{(k-1)}+\left(r_{1}+\Delta r_{1}\right) N_{2}^{(k-1)}, \\
& N_{2}^{(k)}=\left(r_{2}+\Delta r_{2}\right) N_{1}^{(k-1)}+\left(1-r_{2}-\Delta r_{2}\right) N_{2}^{(k-1)},
\end{aligned}
$$

denoting $\overline{r_{1}}=r_{1}-\Delta r_{1}$ and $\overline{r_{2}}=r_{2}-\Delta r_{2}$. Given that it is a one-dimensional convergence, the fact that the sum of the convergence parameters is equal to 1 represents a step from convergence to convergence, which does not conform to the actual situation. Thus, the current discussion will omit the case where the sum of the convergent parameters is greater than 1. After adding uncertainty, low-efficiency technology may suffer from the extreme situation of technical efficiency retrogression due to the uncertainty of the fusion strategy, where the convergence parameter might be less than 0 . This situation is also taken into account. Thus, in the phase where manufacturing technology promotes information technology, $\overline{r_{2}}>0$ and $\overline{r_{1}}+\overline{r_{2}} \leq 1$. Accordingly, in the informatization-driving-industrialization phase, $\overline{r_{1}}>0$ and $\overline{r_{1}}+\overline{r_{2}} \leq 1$.

Given the state transition, matrix $A=\left(\begin{array}{cc}1-\overline{r_{1}} & \overline{r_{1}} \\ \overline{r_{2}} & 1-\overline{r_{2}}\end{array}\right)$, and the characteristic roots of matrix $A$ can be obtained: $\lambda_{1}=1$ and $\lambda_{2}=1-\overline{r_{1}}-\overline{r_{2}}$ :

$$
N^{(k)}=\frac{1}{\overline{r_{1}}+\overline{r_{2}}}\left(\begin{array}{c}
\overline{r_{2}} a+\overline{r_{1}} b+(a-b) \overline{r_{1}}\left(1-\overline{r_{1}}-\overline{r_{2}}\right)^{k} \\
\overline{r_{2}} a+\overline{r_{1}} b-(a-b) \overline{r_{2}}\left(1-\overline{r_{1}}-\overline{r_{2}}\right)^{k}
\end{array}\right) .
$$

(1) When $\overline{r_{1}}+\overline{r_{2}}=1$, the IOITI system converges to $\left(\begin{array}{l}\overline{r_{2}} a+\overline{r_{1}} b \\ r_{2} a+\overline{r_{1}} b\end{array}\right)$.

(2) When $\left|1-\overline{r_{1}}-\overline{r_{2}}\right|<1$, namely, $0<\overline{r_{1}}+\overline{r_{2}}<1$, the following is obtained:

$$
\lim _{k \rightarrow \infty} N^{(k)}=\left(\begin{array}{l}
\frac{\overline{r_{2}} a+\overline{r_{1}} b}{\overline{r_{1}}+\overline{r_{2}}} \\
\frac{\overline{r_{2}} a+\overline{r_{1}} b}{\overline{r_{1}}+\overline{r_{2}}}
\end{array}\right) .
$$

If $\overline{r_{1}} \geq 0$, the following can be obtained:

$$
a=\frac{\overline{r_{2}} a+\overline{r_{1}} a}{\overline{r_{1}}+\overline{r_{2}}} \leq \frac{\overline{r_{2}} a+\overline{r_{1}} b}{\overline{r_{1}}+\overline{r_{2}}} \leq \frac{\overline{r_{2}} b+\overline{r_{1}} b}{\overline{r_{1}}+\overline{r_{2}}}=b .
$$

The fusion technology efficiency lies between the initial information technology efficiency and the initial manufacturing technology efficiency.

If $\overline{r_{1}}<0$, then

$$
\frac{\overline{r_{2}} a+\overline{r_{1}} b}{\overline{r_{1}}+\overline{r_{2}}}<\frac{\overline{r_{2}} a+\overline{r_{1}} a}{\overline{r_{1}}+\overline{r_{2}}}=a
$$

The integration technology efficiency under uncertainty is lower than the initial information technology 
efficiency, and the enterprise's comprehensive technical efficiency may be seen to retrogress. In other words, the decline in output under the same factor indicates that IOITMT has failed. Moreover, the lower the uncertainty of $\left|\left(\overline{r_{2}} / \overline{r_{1}}\right)\right|$, the lower the integration of technology efficiency.

(3) When $\left|1-\overline{r_{1}}-\overline{r_{2}}\right|>1$, namely, $\overline{r_{1}}+\overline{r_{2}}<0$, the model has no convergent solution, and the manufacturing and information technology do not converge. This situation may lead to a large negative convergence of information technology efficiency, whereby IOITMT system is in a state of instability. When the technology seriously degrades, the IOITI system may face collapse. It may also be the case that the manufacturing technology has developed so rapidly that the importance of integration is no longer significant.

(2) Convergence Model with Time-Varying Convergence Parameters. The equilibrium state of the convergent model discussed in this paper is not the original state. Supposing a convergence point of $N^{(k)}=A N^{(k-1)}$ is $N^{*}$, according to the aforementioned analysis, $N^{*}=(c, c)^{T}$ can be obtained. Then, taking the linear transformation of equation (14), let $\widetilde{N}^{(k)}=N^{(k)}-c$. Considering equations (10) and (11), the following can be obtained:

$$
\begin{aligned}
& \tilde{N}_{1}^{(k)}+c=\tilde{N}_{1}^{(k-1)}+c+r_{1}\left(\tilde{N}_{2}^{(k-1)}+c-\tilde{N}_{1}^{(k-1)}-c\right), \\
& \tilde{N}_{2}^{(k)}+c=\tilde{N}_{2}^{(k-1)}+c+r_{2}\left(\tilde{N}_{1}^{(k-1)}+c-\tilde{N}_{2}^{(k-1)}-c\right) .
\end{aligned}
$$

A model similar to Models (10) and (11) can be obtained, as follows:

$$
\widetilde{N}^{(k)}=A \widetilde{N}^{(k-1)} .
$$

Therefore, it can be proven that the convergence point stability of the convergence Model (14) is equivalent to the original stability of the Model (33).

When the uncertainty is not evenly distributed in each convergence link, the convergence parameter is timevarying. At this point, the convergence model becomes

$$
\tilde{N}^{(k)}=A(k-1) \tilde{N}^{(k-1)} \text {. }
$$

According to Lyapunov's stability theory, the criterion for judging the stability of the original equilibrium state is given as follows.

Lemma 1. Discrete time-varying linear systems $x(k+1)=$ $G(k) x(k), k=0,1,2, \ldots$ are uniformly asymptotically stable if, and only if, for any uniformly bounded and uniformly symmetric positive definite $n \times n$ matrix $Q(k)$, and the following Lyapunov difference equation is applied:

$$
G^{T}(k) P(k+1) G(k)-P(k)+Q(k)=0 .
$$

Here, there exists only a uniformly bounded and uniformly symmetric positive definite solution to $P(k)$.
Since the determination of $G(k)$ is not straightforward, it is difficult to judge the stability of the convergence model using lemma. Given the implications of convergence parameters, the discussion of time-variants can be turned into a discussion of parameter uncertainty, where the convergence parameter is the embodiment of the additional uncertainty of a certain value.

Supposing the uncertain $\Delta A$ of matrix $A$ is modularbounded interference and satisfies $|\Delta A|\langle\alpha, \alpha\rangle 0$, the stability of equation (34) is equivalent to

$$
\tilde{N}^{(k)}=(A+\Delta A) \tilde{N}^{(k-1)},
$$

where $\Delta A$ is a random variable. A further simulation analysis is detailed in the next section.

(3) Integration Quality under Uncertainty. To sum up, uncertainty will greatly affect the integration effect, and it is particularly critical to reducing the artificial negative influence. So, how much does uncertainty affect integration? The current section discusses this in the case of convergence.

In an ideal state, the technical efficiency of manufacturing enterprises corresponding to convergence is $\left(r_{2} a+r_{1} b / r_{1}+r_{2}\right)$, the actual output corresponding to uncertainty interference is denoted as $Q_{\text {integration, }}$ and the difference in output can be regarded as the output deviation caused by uncertainty.

Therefore,

$$
\widetilde{Q}=\left|Q_{\text {integration }}-Q_{\text {ideal }}\right| \text {. }
$$

When $Q_{\text {integration }}<Q_{\text {ideal }}, \widetilde{Q}$ is the deviation cost; when $Q_{\text {ideal }}<Q_{\text {integration }}, \widetilde{Q}$ represents coordinated benefits. As previously mentioned, there are uncertainties inside and outside the fusion system, with much of the internal uncertainty caused by human factors capable of manual control; the external uncertainties fed back into the system by internal factors can also be adjusted by human factors. Therefore, there is enough room for system development to play the role of human resources. In fact, in order to obtain the actual measurement $\widetilde{Q}$, we can simply calculate $Q_{\text {ideal }}$ and the actual output.

The deviation represents the degree to which the integration deviates from the ideal technical efficiency, denoted as

$$
q=\frac{Q_{\text {integration }}-Q_{\text {ideal }}}{Q_{\text {ideal }}},
$$

where $q$ is the integration quality coefficient representing the integration quality of IOITMT. If $q<0$, this shows that uncertainty incurs a cost of deviation, whereby the lower the integration quality coefficient $q$, the worse the integration quality. If $q \geq 0$, this shows that uncertainty brings coordinated benefits, and the higher the integration quality coefficient $q$, the higher the integration quality.

\subsection{Simulation Analysis}

7.3.1. Influence of Convergence Parameters on Technical Convergence. It is assumed that the technical efficiency of a manufacturing enterprise is 0.6, and the influence of 
convergence parameters on this efficiency is considered in a convergence cycle of IOITMT:

(1) Technical efficiency evolution under the same proportion of convergence parameters

A specific proportion $\left(r_{1} / r_{2}\right)=(5 / 3), r_{1}=0.1$, and $r_{2}=0.06$. $a=0.6$ and $b=1$ lead to the following analysis of integration technology efficiency:

$$
c=a+\frac{b-a}{1+\left(r_{2} / r_{1}\right)}=0.85
$$

Retaking $r_{1}=0.05$ and $r_{2}=0.03$, there is the same technical efficiency as above, $c=0.85$.

MATLAB was used to draw the evolution curve of technical efficiency under the convergence model, as shown in Figure 12.

It can be seen that, in a convergence period, the technical convergence efficiency is equal under the same proportion, and convergence converges to the same point, which also verifies the aforementioned conclusion. Moreover, through observation, it can be seen that when the convergence parameters of inefficient technology are larger, the amount of convergence will be less, and the matching state will be easier to achieve.

(2) Technical efficiency evolution under different proportions of convergence parameters

Next, the convergence conclusion and evolution trajectory are compared between $\left(r_{1} / r_{2}\right)=(5 / 3), r_{1}=0.1$, and $r_{2}=0.06$ with $r_{1} / r_{2}=1, r_{1}=0.05$, and $r_{2}=0.05$.

When $r_{1} / r_{2}=1, r_{1}=0.05$, and $r_{2}=0.05$, it is possible to calculate the integration of technical efficiency as 0.8 . Now, we plot the evolution trajectory of technical efficiency under different proportions of convergence parameters.

As shown in Figure 13, under the same conditions, the proportion of convergence parameters determines the value of the integration of technical efficiency. The larger the proportion, the greater the integration of technical efficiency.

7.3.2. Impact of Uncertainty on Technical Convergence. In view of the situation $r_{1}=0.1, r_{2}=0.06$, and $a=0.6, b=1$, it was assumed that convergence changes around the established numerical parameters and obeys a normal distribution. Using MATLAB simulation analysis, the following was obtained, as shown in Figure 14:

(1) $r_{1} \sim N(0.1,0.3)$ and $r_{2} \sim N(0.1,0.3)$

After many simulation comparisons, the integration of technology efficiency of information and manufacturing technology was found to reach 0.85 consistently across different convergence times.

(2) $r_{1} \sim N(0.1,0.7)$ and $r_{2} \sim N(0.1,0.7)$

When the standard deviation changes to 0.7 , the results of multiple simulations are very different, and the technical

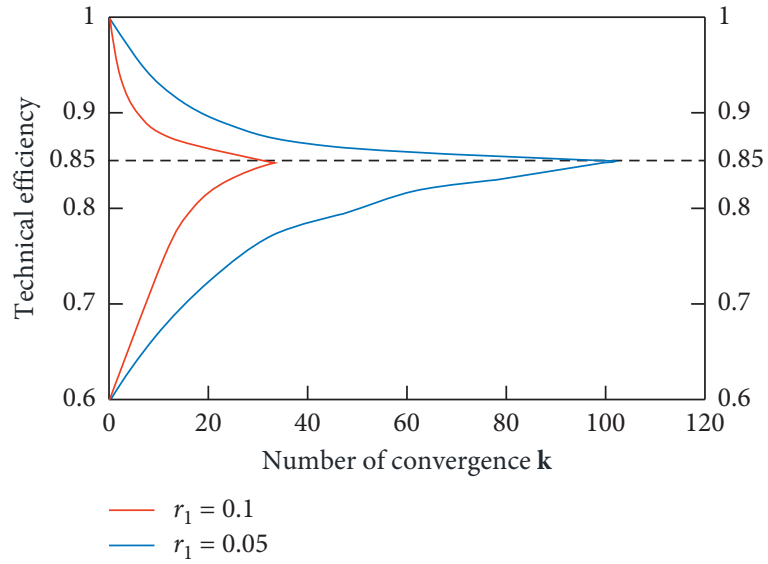

FIGURE 12: Evolution trajectory of technical efficiency under the same proportion of convergence parameters.

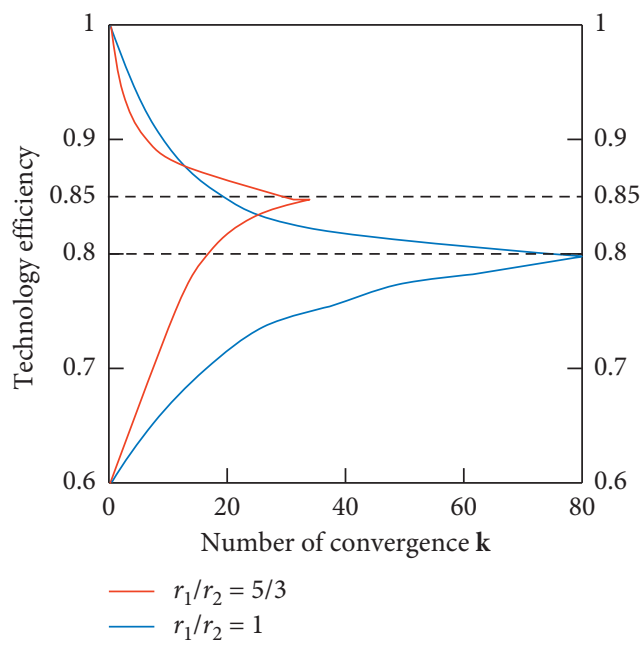

FIgURE 13: Evolution trajectory of technical efficiency under different proportions of convergence parameters.

efficiency is difficult to converge. Two conditions of this uncertain analysis appear, as shown in Figure 15. In light of these, it is crucial to grasp the positive effect of uncertainty and minimize the negative impact on IOITMT.

\section{Practical Recommendations for IOITMT}

This paper was discussed based on the three stages of IOITMT, the order parameters of different stages, and the evolution of IOITMT system convergence under servitude. The following suggestions are proposed for IOITMT construction of manufacturing enterprises:

(1) Master the dominant role of order parameters. There are different order parameters in different stages when enterprises evaluate their own level of integration and technical conditions. Therefore, determining the order parameters is helpful in establishing current development priorities. The bottleneck of information technology should be emphasized at the stage of manufacturing 


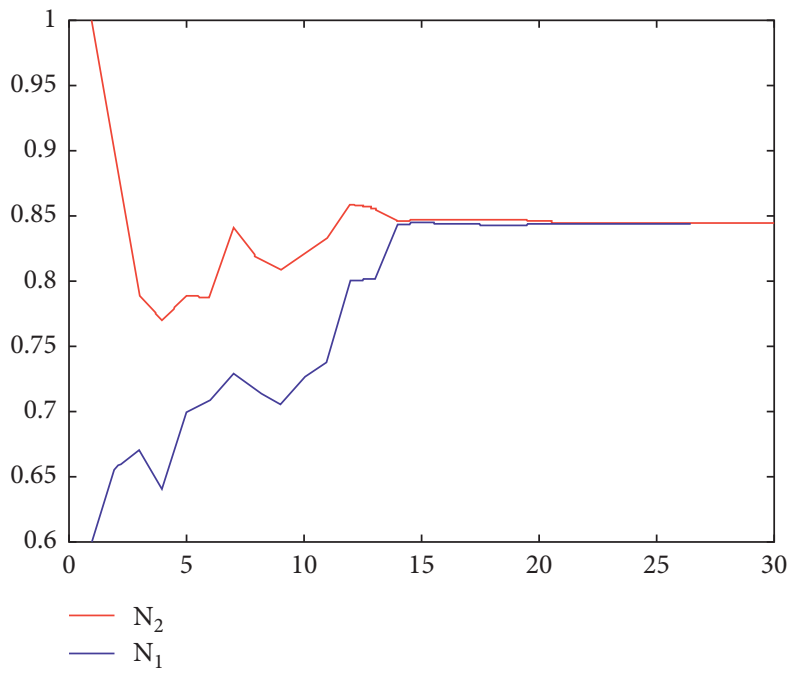

FIGURE 14: Influence of uncertainty on the integration of technology efficiency with $r_{1} \sim N(0.1,0.3)$ and $r_{2} \sim N(0.1,0.3)$.

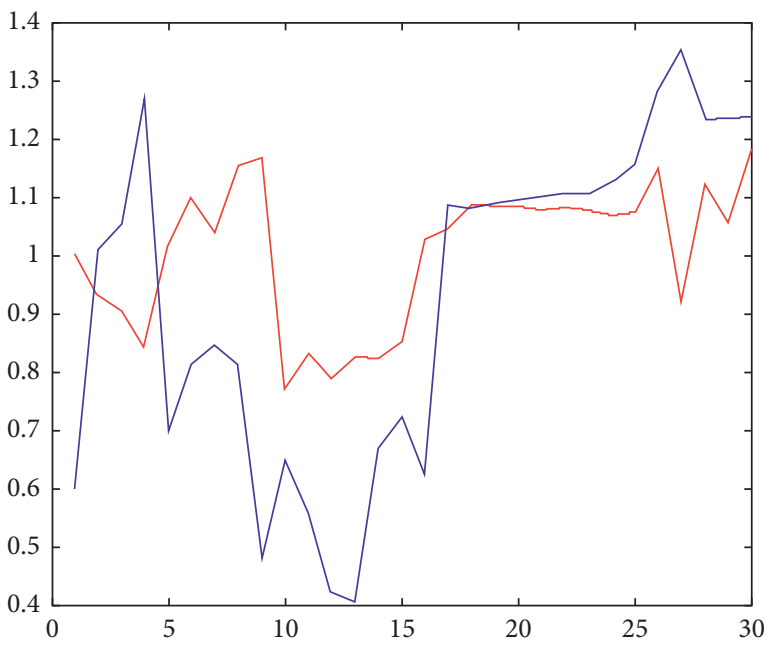

(a)

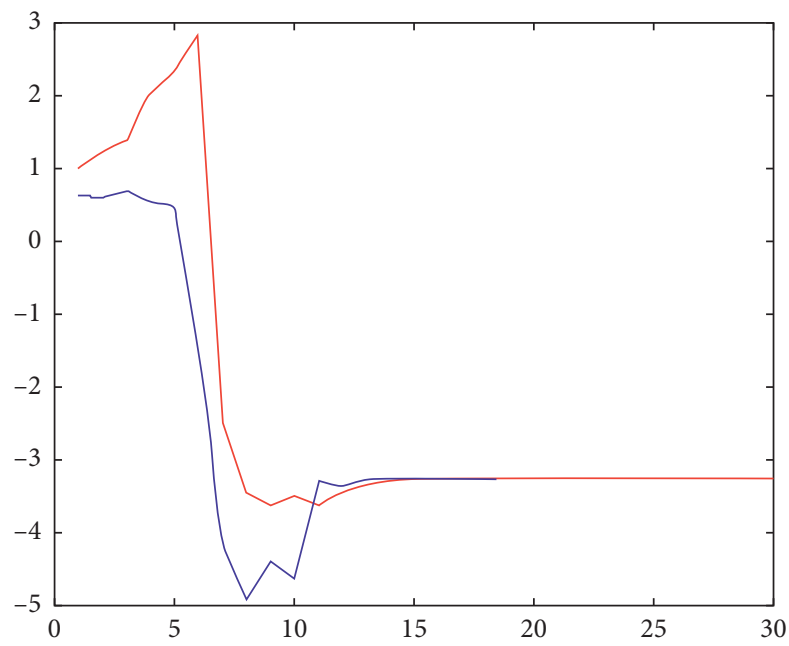

(b)

FiguRE 15: Influence of uncertainty on the integration of technology efficiency with (a) $r_{1} \sim N(0.1,0.7)$ and (b) $r_{2} \sim N(0.1,0.7)$.

technology promoting information technology. However, in the information technology driving manufacturing technology stage, manufacturing enterprises should focus on improving the construction of manufacturing technology-related aspects.

(2) Pay attention to the relationship between technological efficiency and IOITMT. The dynamic change in technological efficiency and the progress of IOITMT go hand-in-hand, and the evolution of technological efficiency is also one of the macroscopic characteristics of integration. This paper links the economic benefits of enterprises with IOITMT. Hence, enterprises can determine their internal technology configuration status based on the change in total factor productivity, starting from the macrotechnical efficiency to find the root and source, and then following up IOITMT.
(3) Pay attention to the leading role of technological progress in order to achieve cross-cycle convergence and technological efficiency of step development. This paper does not include the introduction technological progress in the period discussed because such progress leads to the lapse of the frontier and imbues convergence with a dual nature. The convergence analysis in this paper reveals that the technological progress within an enterprise is the main basis for dividing the cycle. If the enterprise can maintain this progress in light of the external technical environment and update its technology in a timely manner and within the available budget, the convergence of this cycle can be ended ahead of time and the convergence of the next cycle can be entered, ultimately meaning that the technical efficiency can effectively improve in leaps and bounds. 


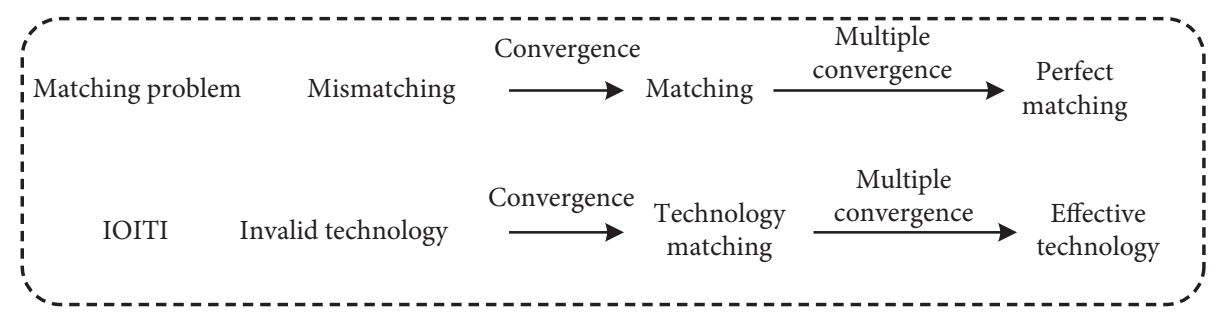

FIGURE 16: Convergence evolution path of matching problem.

(4) Regulate convergence parameters to improve the integration of technology efficiency. Research shows that the ratio of two technical efficiency convergence parameters decides the integration efficiency of IOITMT because, being a representation of the convergence of manufacturing technology and information technology, convergence parameters are considerably subject to the influence of management decisions. Therefore, it is feasible and effective to improve the quality of IOITMT by regulating convergence parameters and improving the integration of technology efficiency. Based on the conclusions given in this paper, the lower the $\left(r_{1} / r_{2}\right)$, the lower the degree of fusion technology efficiency. Therefore, focusing on the rapid improvement of inefficient technologies is an effective way to improve the comprehensive technical efficiency of enterprises and increase the output rate.

(5) Attach importance to the impact of uncertainty and try to improve coordination benefits and eliminate deviation costs. In reality, IOITMT cannot always be smooth, as unexpected results can also emerge. Therefore, it is feasible to recognize uncertainty correctly and regulate it appropriately through managerial decision-making, systems analysis, empirical judgment, and other methods, ultimately guiding the correct development of uncertainty in a benign direction, and optimizing the impact of uncertainty.

\section{Conclusion}

Based on the self-organizing evolution theory model of technical efficiency, this paper analyzed and determined the order parameters and discussed the evolution mode of technical efficiency in three stages under the guidance of order parameters, with reference to convergence theory, as shown in Figure 16. The main theoretical contributions are as follows:

(1) Order parameter and technical efficiency are interlinked. In this paper, the lower technical efficiency at each stage was selected as the order parameter. The lower technical efficiency, defined by the barrel principle, is equal to the technical efficiency of the enterprise, which also means that the lower efficiency reflects the overall performance and restrains the development of the enterprise's technical efficiency, thus connecting the concepts of order parameters and technical efficiency by definition and meaning.
(2) Integration and convergence. To the best of our knowledge, this paper is the first attempt to connect integration and convergence within microenterprises. Such an idea can be extended to other integration problems. For example, "Internet+" refers to the combination of Internet technology and other industrial businesses and technologies. Its essence should be the integration of the Internet and other industries, that is, convergence. This also constitutes a further research direction and research focus.

(3) Introduction of the concept of the technical efficiency of internal technology. Research on technical efficiency can be divided into two categories: research on the productivity of macroobjects, such as countries and industries, and discussions of the overall performance of enterprises or units. It is a bold attempt in theory and application to introduce the technical efficiency of enterprises for microanalysis, and this paper also presented a new method for dealing with the integration problem.

(4) Improvement and discussion of convergence theory and methods. The concept of convergence originates from the theory of economic growth. This paper introduced convergence theory into the field of management science. This research yielded the following innovations: (1) improvements to the convergence model and two-dimensional heterogeneous convergence; (2) the introduction of "matching" and "perfect matching," which allows heterogeneous convergence to be discussed on a uniform scale; (3) a revised meaning of convergence parameters and their causes; (4) the analysis of technical efficiency equating one-dimensional convergence with twodimensional convergence, the conclusion of which can be extended to the problem of high-dimensional heterogeneous convergence; (5) a preliminary discussion of an uncertainty analysis in the process of convergence, highlighting that uncertainty is inevitable in the process of convergence and greatly affects the convergence results; (6) the discussion of convergence quality through the convergence study of technical efficiency. Although there is still much work to be done on the convergence theory and method, the conclusions of this paper will, it is hoped, prove to be of great significance to this body of research.

(5) The connection between matching and convergence. Matching problems are very common in real life, and 
integration problems can be considered as part of these. In this paper, integration is analyzed from the perspective of matching, and the conclusions and methods obtained are also applicable to other matching problems. Based on the concept given in this paper, matching, integration, and convergence are combined.

The theoretical analysis and methods of the current research represent a new attempt which, while obtaining certain key findings, still contains the following limitations:

(1) The discussion of convergence parameters is insufficient. In order to discuss idealization, it is assumed that convergence parameters are constant. In reality, convergence parameters are time-varying and related to many factors. The design of the method used to measure convergence parameters, thus, requires further research.

(2) Assume that a convergence period does not consider the scale effect and technological progress. Even though, through convergence, the cycle length can be appropriately divided to avoid the scale effect and the influence of technological progress, this paper included no discussion on the continuous integration of technological pursuits and material supplements, namely, the cross-cycle jump integration described, which is also an aspect to be included in the followup research.

\section{Data Availability}

All the research data and simulation code in this paper can be obtained by contacting the corresponding author Jianhua Zhuviabmjianhua@mail.scut.edu.cn.

\section{Conflicts of Interest}

The authors declare that they have no conflicts of interest.

\section{References}

[1] M. El-Mekawy, L. Rusu, and E. Perjons, "An evaluation framework for comparing business-IT alignment models: a tool for supporting collaborative learning in organizations," Computers in Human Behavior, vol. 51, pp. 1229-1247, 2015.

[2] P. Glowalla and A. Sunyaev, "ERP system fit-an explorative task and data quality perspective," Journal of Enterprise Information Management, vol. 27, no. 5, pp. 668-686, 2014.

[3] F. Rahimi, C. Møller, and L. Hvam, "Business process management and IT management: the missing integration," International Journal of Information Management, vol. 36, no. 1, pp. 142-154, 2016.

[4] J. C. Henderson and H. Venkatraman, "Strategic alignment: leveraging information technology for transforming organizations," IBM Systems Journal, vol. 32, no. 1, pp. 472-484, 1993.

[5] B. H. Reich and I. Benbasat, "Measuring the linkage between business and information technology objectives," MIS Quarterly, vol. 20, no. 1, pp. 55-81, 1996.
[6] J. Luftman and T. Brier, "Achieving and sustaining businessIT alignment," California Management Review, vol. 42, no. 1, pp. 109-122, 1999.

[7] B. Campbell, R. Kay, and D. Avison, "Strategic alignment: a practitioner's perspective," Journal of Enterprise Information Management, vol. 18, no. 6, pp. 653-664, 2005.

[8] D.-L. Shi and J.-Z. Pan, "Investment to IT for business value: a prospect of IT and business fusion," Soft Science, vol. 20, no. 5, pp. 9-15, 2006.

[9] P. J. Pyburn, "Linking the MIS plan with corporate strategy: an exploratory study," MIS Quarterly, vol. 7, no. 2, pp. 1-14, 1983.

[10] M. Broadbent and P. Weill, "Improving business and information strategy alignment: learning from the banking industry," IBM Systems Journal, vol. 32, no. 1, pp. 162-179, 1993.

[11] P. Bhattacharya, "Modelling strategic alignment of business and IT through enterprise architecture: augmenting archimate with BMM," Procedia Computer Science, vol. 121, pp. 80-88, 2017.

[12] N. A. Zaguir, M. de Mesquita Spinola, and F. J. B. Laurindo, "Business modeling toward competitiveness and ciboria's criticism: results from an IT-business strategic alignment via an action-research," in IFIP Advances in Information and Communication Technology, vol. 488, pp. 239-247, Springer, Berlin, Germany, 2016.

[13] A. Belalcázar, M. B. Ron, J. Díaz, and L. Molinari, “Towards a strategic resilience of applications through the NIST cybersecurity framework and the strategic alignment model (SAM)," in Proceedings of the International Conference on Information Systems and Computer Science, pp. 181-187, Quito, Ecuador, November 2017.

[14] L. Fraccascia, V. Albino, and C. A. Garavelli, "Technical efficiency measures of industrial symbiosis networks using enterprise input-output analysis," International Journal of Production Economics, vol. 183, pp. 273-286, 2017.

[15] R. van de Wetering and P. Mikalef, "The effect of strategic alignment of complementary IT and organizational capabilities on competitive firm performance," Business Information Systems Workshops, vol. 303, pp. 115-126, 2017.

[16] A. Salaheddine and C. Ilias, "Continuous improvement of strategic alignment model," Lecture Notes in Networks and Systems, vol. 25, pp. 12-20, 2017.

[17] Y. E. Chan, S. L. Huff, D. W. Barclay, and D. G. Copeland, "Business strategic orientation, information systems strategic orientation, and strategic alignment," Information Systems Research, vol. 8, no. 2, pp. 125-150, 1997.

[18] Y. E. Copeland, "Information systems strategy, structure and alignment," in Strategic Information Technology: Opportunities for Competitive Advantage, pp. 82-104, IGI Global, Hershey, PA, USA, 2001.

[19] S. M. Chege, D. Wang, and S. L. Suntu, "Impact of information technology innovation on firm performance in Kenya," Information Technology for Development, vol. 11, pp. 1-30, 2019.

[20] M. V. Pai, S. Mayya, and H. G. Joshi, "An empirical study on characteristics which leads to innovation: with reference to information technology sector," in Innovations in Computer Science and Engineering, pp. 309-315, Springer, Berlin, Germany, 2019.

[21] T. S. Mclaren, M. M. Head, and Y.-F. Yuan, “A multilevel model for measuring fit between a firm's competitive strategies and information systems capabilities," MIS Quarterly, vol. 35, no. 4, pp. 909-930, 2011. 
[22] E. A. A. Seman and J. Salim, "A model for business-IT alignment in Malaysian public universities," Procedia Technology, vol. 11, no. 1, pp. 1135-1141, 2013.

[23] V. Goepp and O. Avila, "An extended-strategic alignment model for technical information system alignment," International Journal of Computer Integrated Manufacturing, vol. 28 , no. 12 , pp. 1-16, 2015.

[24] V. Dutot, F. Bergeron, and L. Raymond, "Information management for the internationalization of SMEs: an exploratory study based on a strategic alignment perspective," International Journal of Information Management, vol. 34, no. 5, pp. 672-681, 2014.

[25] A. Renaud, I. Walsh, and M. Kalika, "Is SAM still alive? A bibliometric and interpretive mapping of the strategic alignment research field," The Journal of Strategic Information Systems, vol. 25, no. 2, pp. 75-103, 2016.

[26] M. J. Farrell, "The measurement of productive efficiency," Journal of the Royal Statistical Society. Series A (General), vol. 120, no. 3, pp. 253-290, 1957.

[27] S. N. Afriat, "Efficiency estimation of production functions," International Economic Review, vol. 13, no. 3, pp. 568-598, 1972.

[28] B. Walheer, "Labour productivity growth and energy in Europe: a production-frontier approach," Energy, vol. 152, no. 1, pp. 129-143, 2018.

[29] A. Otsuka, "Regional determinants of total factor productivity in Japan: stochastic frontier analysis," The Annals of Regional Science, vol. 58, no. 3, pp. 579-596, 2017.

[30] W. W. Cooper, L. M. Seiford, and K. Tone, Data Envelopment Analysis: A Comprehensive Text with Models, Applications, References and DEA-Solver Software, Kluwer Academic Publishers, Berlin, Germany, 2007.

[31] S. Chen, Y.-Q. Feng, C. Lin, and C. Zhang, "Innovation efficiency evaluation of new and high technology industries based on DEA-malmquist index," Journal of Interdisciplinary Mathematics, vol. 20, no. 6-7, pp. 1497-1500, 2017.

[32] C. J. O'Donnell, S. Fallah-Fini, and K. Triantis, "Measuring and analysing productivity change in a metafrontier framework," Journal of Productivity Analysis, vol. 47, no. 2, pp. 117-128, 2017.

[33] M. A. Toro and A. Mäki-Tanila, "Some intriguing questions on Fisher's ideas about dominance," Journal of Animal Breeding and Genetics, vol. 135, no. 3, pp. 149-150, 2018.

[34] M. Abramovitz, "Catching up, forging ahead, and falling behind," The Journal of Economic History, vol. 46, no. 2, pp. 385-406, 1986.

[35] W. J. Baumol and E. N. Wolff, "Productivity growth, convergence, and welfare: what the long-run data show," American Economic Review, vol. 76, no. 5, pp. 1072-1085, 1986.

[36] J. Lottes, Towards Robust Algebraic Multigrid Methods for Nonsymmetric Problems, Springer International Publishing, Berlin, Germany, 2017.

[37] S. N. Durlauf and P. A. Johnson, "Multiple regimes and crosscountry growth behaviour," Journal of Applied Econometrics, vol. 10, no. 4, pp. 365-384, 1995. 